\title{
Redescubrimiento de los servicios sociales de atención primaria: hacia un (nuevo) modelo de atención personal y comunitaria
}

\section{José María Duque Carro}

Trabajador social

<txema.duque@ayto.bilbao.net>

Urteetako garapena ezagutu ostean, EAEko gizarte-zerbitzuen testuinguru berrian erabateko garrantzia dute honako gaiek: mendekotasunegoerei aurre egiteko prestazioen kudeaketa, Diru-sarbideak Bermatzeko Errenta eta Etxebizitza Ordaintzeko Prestazioen kudeaketaren tokialdatzea eta egun onartutako Gizarte Zerbitzuen Legearen garapena. Hori guztia gertatzen da krisialdi sakon baten aroan. Bertan aldentzen da berriz ere egin beharreko gizarte-zerbitzuen formulazioa, eta laguntze sozialean oinarritutako arreta pertsonal eta komunitarioa garatzearen alde, bertan jasotzen direlarik eraginkorrak izan daitezkeen zenbait proposamen.

\section{HITZ-GAKOAK:}

gizarte-zerbitzuak, lehen-mailako arreta, eredu komunitarioa, garapen pertsonala, laguntze soziala.
Tras años de desarrollo, los servicios sociales en la CAPV se encuentran en un nuevo contexto marcado sobre todo por la gestión de las prestaciones de la dependencia, el traslado de la Renta de Garantía de Ingresos y la Prestación Complementaria de Vivienda al sistema de empleo y el desarrollo de la última Ley de Servicios Sociales. Todo ello en un momento de profunda crisis económica. En este artículo se defiende la pertinencia y oportunidad de una reformulación de los servicios sociales y aboga por el desarrollo de un modelo de atención personal y comunitaria basado en el acompañamiento social, incluyendo una serie de propuestas operativas.

\section{Palabras Clave:}

servicios sociales, atención primaria, modelo comunitario, desarrollo personal, acompañamiento social. 


\section{Introducción}

Durante la etapa democrática, los servicios sociales de la CAPV han tenido un gran desarrollo. Las políticas públicas de lucha contra la pobreza y la exclusión se han visibilizado fundamentalmente a través del gran aumento de las prestaciones económicas. Los servicios sociales de base, planteados como puerta de entrada al sistema, muy pronto (1989) se vieron condicionados y absorbidos por el protagonismo de estas prestaciones y su gestión.

En este camino (han pasado más de veinte años), los y las profesionales nos hemos debatido constantemente entre el ser y el deber ser de nuestra intervención con las personas que solicitan ayuda. En este contexto de autocrítica permanente (y sin salida), muchas y muchos profesionales hemos intentado adaptarnos, sobreviviendo así a una práctica que nos ha encerrado en el despacho, más centrados en la gestión de recursos y menos en el acompañamiento a las personas. El modelo de atención de los servicios sociales de base se ha convertido, en general, en un modelo burocratizado y esclerotizado.

Este artículo es una síntesis del trabajo de fin de Grado en Trabajo Social presentado en junio de 2012 y nace de una intuición compartida: estamos ante una gran oportunidad de recuperar eso que denominamos ‘lo esencial’, ‘lo genuino’ de la intervención social. Estamos ante un proceso complejo en el que debemos responder a si podemos, si sabemos y si queremos llevarlo a cabo. En este proceso de recuperación será importante la decisión política, la capacidad técnica y de actitud de los profesionales (atención a las resistencias). En este sentido, es preciso fomentar el debate técnico que facilite a los responsables políticos la toma de decisiones consecuentes que hagan posible el desarrollo de este (nuevo) modelo.

\section{Aquí y ahora de los Servicios Sociales en la CAPV: una visión crítica}

Han pasado treinta años desde nuestra primera ley de servicios sociales (1982). En estos años se han producido avances considerables 1 . No obstante, tengo que decir que formo parte de ese grupo de profesionales que, trabajando y creyendo en los servicios sociales, vivimos una cierta decepción causada por la sensación de que el Sistema Vasco de Servicios Sociales (en adelante SVSS), no está donde le correspondería por edad y recursos invertidos. Nos queda mucho por hacer.

${ }^{1}$ Todo ello ha ido apareciendo de alguna forma en los nueve informes del Consejo Vasco de Bienestar Social, en las comparecencias de la ponencia del Parlamento previa a la Ley $12 / 2008$ de Servicios Sociales y en distintos foros de profesionales. Sobre la situación a escala estatal -salvo las mejoras producidas por la Ley de Autonomía y Dependencia- puede verse Sarabia (2007). El desigual desarrollo en el Estado también puede verse en Uceda-Maza y García-Muñoz (2010).
El SVSS ha crecido en cantidad y calidad, pero quizás sin utilizar los mecanismos y procesos que garantizasen su afianzamiento, su madurez y su identidad. A partir de nuestra segunda Ley de Servicios Sociales (1996) y en un contexto de bonanza económica, nuestra comunidad ha perdido la oportunidad de desarrollar un sistema equilibrado y con acceso homogéneo a prestaciones y servicios para toda la ciudadanía de los tres Territorios Históricos. Este desarrollo se ha visto condicionado fundamentalmente por la Ley de Territorios Históricos (1983) y por el insuficiente desarrollo legislativo de la Ley de Servicios Sociales de 1996.

La Ley $12 / 2008$ surge del consenso de todos los grupos políticos en el tramo final de una legislatura, recién iniciado un periodo de crisis económica en el que todavía nos encontramos inmersos.

Es preciso situar esta opinión crítica en este momento concreto, en el que la Ley 12/2008 todavía no tiene incidencia efectiva alguna en el sistema de servicios sociales, ya que no tiene desarrollados sus principales instrumentos como son la Cartera de Prestaciones y Servicios y el Mapa de Servicios Sociales.

\subsection{Sobre el Sistema Vasco de Servicios Sociales en su conjunto}

Se señalan a continuación, de forma muy resumida, algunas de las características que a mi juicio definen la actual situación del Sistema Vasco de Servicios Sociales en su conjunto.

- La división competencial ha dificultado el liderazgo de las Administraciones Públicas para promover un modelo de intervención común en la CAPV. Ello hace que la ciudadanía no pueda visibilizar ni identificar los servicios sociales como partes integrantes de un sistema. Nadie ha asumido un liderazgo necesario y que, en su ausencia, ha desembocado en tres modelos forales y 251 municipales.

- No ha existido concepción de sistema único. En consecuencia, no podemos hablar de un desarrollo y despliegue homogéneo y ordenado, respondiendo a una cierta planificación. Los dos niveles de atención -primario y secundario- responden a dinámicas propias de dos sistemas. Los Servicios Sociales de Base (en adelante, SSB) no han sido, en la práctica, la puerta única de entrada al sistema. Contingencias como la discapacidad o la exclusión han transitado por distintas puertas de acceso al sistema. Necesitamos dotarnos de un verdadero sistema de servicios sociales, estructurado y coordinado con otros sistemas. Con herramientas homogéneas de planificación, diagnóstico y evaluación.

- El sistema de servicios sociales es un sistema en construcción. Se encuentra menos consolidado y reconocido que otros, como el sanitario 
o el educativo, siendo todos ellos importantes en la protección y el bienestar social. Hemos de avanzar hacia un sistema visible y reconocible. Es necesaria esta reestructuración para evitar que los servicios sociales se mantengan a una situación esclerotizada, fragmentaria y residual.

- Desigualdad en las condiciones laborales. El personal subcontratado dispone de unas condiciones laborales claramente peores que el personal contratado directamente por la Administración. La modalidad de gestión indirecta de servicios sociales está regulada por una serie de convenios bastante distintos entre sí, como el convenio de Intervención Social (único para la CAPV), los convenios de SAD, distintos para cada Territorio Histórico o los correspondientes a la atención residencial de personas mayores. Existen además convenios de empresa, sobre todo en el ámbito de la discapacidad, que establecen condiciones laborales muy diferentes a las que se establecen en los respectivos convenios sectoriales o territoriales.

- Retroceso en las coberturas sociales de personas en riesgo o situación de exclusión social. A causa del endurecimiento de los requisitos de acceso (aumento de 1 a 3 años el tiempo de empadronamiento y limitación de dos rentas por vivienda, así como la denegación de RGI en recursos residenciales de acogida temporal) y la disminución de un $7 \%$ del presupuesto para la Renta de Garantía de Ingresos y Prestación Complementaria de Vivienda, se está produciendo un aumento de personas en situación o riesgo de exclusión².

- La CAPV ocupa en 2012 el primer lugar en España en relación al gasto social ${ }^{3}$. El gasto anual por habitante se sitúa en 773 euros en la CAPV, siendo las Comunidades Autónomas más cercanas Navarra (488 euros), Castilla-La Mancha (467 euros), Cantabria (370 euros) y La Rioja (363 euros) y Extremadura (353 euros). El gasto medio anual de España es 280 euros por habitante.

- No disponemos de un sistema adecuado de información que nos proporcione la información de la actividad del conjunto de la CAPV de forma ágil, actualizada y que esté al servicio de la mejora y evaluación del sistema4.

\subsection{Sobre los Servicios Sociales de Atención Primaria $^{5}$}

En relación, específicamente, a los Servicios Sociales de atención primaria, cabe hacer las siguientes consideraciones:

2 Según consta en el informe anual del Ararteko de 2011, las quejas de la ciudadanía relacionadas con el sistema de protección social han aumentado un $320 \%$.

3 Véase García Herrero y Ramírez Navarro (2012).

${ }^{4}$ En este momento se encuentra en proceso de elaboración el Sistema Vasco de Información sobre Servicios Sociales.

${ }_{5}^{5}$ Para una situación panorámica de los servicios sociales, véase Arenas (2011)
- Constituyen el eslabón más débil del pretendido sistema. La Ley 6/1982 no hacía mención a los Servicios Sociales de Base, si bien podemos entender que de forma genérica, se citan algunas líneas que, a posteriori, hemos visto relacionadas con ellos ${ }^{6}$. En la Ley 5/1996 se consideró a los Servicios Sociales de Base como la unidad básica del sistema pero no se les otorgó -en la prácticani el reconocimiento, ni los medios personales y materiales necesarios para el desarrollo de sus funciones.

- La heterogeneidad, a la larga, ha agudizado las diferencias. La indefinición conceptual mantenida en el tiempo se ve como origen del desarrollo desigual y diverso de los servicios y programas. Aunque sobre el papel, constituyen la red de atención primaria del sistema de servicios sociales, en la práctica, se basan en definiciones vagas e imprecisas, y así su desarrollo se ha manifestado en una proliferación de servicios locales, con diversas denominaciones, contenidos, programas, organización y procedimientos?

- Los Servicios Sociales de Base se han visto sometidos durante muchos años a un proceso de burocratización de la atención que les ha ido incapacitando de hecho -en disponibilidad de tiempo y capacidad técnica- progresivamente para la adecuada atención de las personas atendiendo a criterios y metodología de atención social individualizada e integral. Todo ello ha producido en los equipos profesionales un desbordamiento y desmotivación que habrá que tener necesariamente en cuenta en estos momentos.

- La práctica mayoritaria de tramitación de prestaciones económicas ha conformado una práctica profesional de tipo administrativo, caracterizada por el trabajo de despacho y las tareas de comprobación de requisitos, situándose así muy lejos de la dinámica relacional individual y familiar y, aún más, de las dinámicas comunitarias.

- Los Servicios Sociales de Base no han contado con las herramientas, la formación y la terminología necesarias para una intervención social suficientemente orientada hacia una práctica profesional consensuada. Tampoco han dispuesto de un sistema homogéneo de información, con indicadores de demanda que permitan los análisis comparativos y una planificación que vaya adecuando los recursos a las necesidades de la ciudadanía.

- No ha habido disposiciones claras respecto a la valoración de necesidades o diagnóstico. Siempre hemos hecho una cierta valoración y diagnóstico pero quizás de una forma no sistematizada y basada más en exploraciones espontáneas y

\footnotetext{
${ }^{6}$ Concretamente, los artículos 3, 5 y 11 al 16.
}

${ }^{7}$ En realidad el proceso de implantación de los servicios sociales de base ha venido marcado por la necesidad de contratación de trabajadores sociales para el desarrollo del Programa de Ayuda a Domicilio y el Plan de Lucha contra la Pobreza. Progresivamente se les fueron añadiendo otras funciones propias, en ocasiones más y en otras menos, de un Servicio Social de Base. 
nada sistemáticas. Más bien fiadas éstas al saber hacer de cada profesional aunque condicionadas al tiempo disponible y a la capacidad técnica, interés o sensibilidad de cada profesional.

Para terminar este repaso crítico del aquí y el ahora de los Servicios Sociales, señalaré algunos puntos débiles en la Ley 12/2008 de Servicios Sociales, especialmente relevantes en lo que se refiere a la definición de la atención primaria:

- Perfiles profesionales. Se establece como el profesional básico y de referencia al trabajador social. No se avanza más en cuanto a la composición profesional de los equipos. No se trata qué papel van a jugar otros profesionales en los servicios de la Cartera. Tampoco se establece en la propia Cartera. Quizás se necesita un decreto para los Servicios Sociales de Base.

- Continuidad de la atención. La ley la establece incluso desde los principios (artículo 7.f) pero no queda suficientemente explicitado el sistema de coordinación entre sistemas ni entre la atención primaria y la secundaria. Este aspecto puede presentar dificultades especiales en relación a la intervención en el ámbito de la exclusión por ser ésta una contingencia con aspectos diferenciales significativos respecto a la desprotección y la dependencia.

- La prescripción técnica. Equilibrio entre el derecho subjetivo, la participación de la ciudadanía y el grado de idoneidad de las prestaciones y servicios establecido por la prescripción técnica profesional. Su lugar hay que situarlo entre los déficit diagnosticados (nivel de gravedad de la contingencia) y la intensidad de apoyo profesional aceptada por la persona libremente.

- Valoración y diagnóstico especializado. La Ley lo establece como vinculante (artículo 30. 2), si bien, teniendo en cuenta la práctica habitual y tratando de evitar el perjuicio para la ciudadanía, sería conveniente prever un medio de resolución de las discrepancias que puedan darse. Lo más adecuado sería situar este servicio en el ámbito de la acción directa del Gobierno Vasco o bien podría establecerse un órgano técnico mixto con capacidad para resolver en esta cuestión.

- Ambigüedad respecto a la competencia para intervenir en las situaciones de emergencia y urgencia social. Se hace necesaria una interpretación que aclare la confusión existente entre el artículo 27.2 a) -en el que sitúa la competencia en la atención primaria, si bien parece asimilar 'situación de urgencia' con 'desprotección social'y el artículo 22. 2.6 -Servicio de Coordinación a Urgencias Sociales- que queda recogido en el Catálogo de Prestaciones y Servicios. Quizás lo más operativo sea que el Servicio de coordinación sea de acción directa del Gobierno Vasco (integrado en el 112, como el Servicio de Urgencias Médicas) y la atención in situ (valoración de necesidades y derivación) esté en el ámbito municipal con prestación individual o mancomunada.
- Profesional de referencia y proceso de coordinación de caso. No queda claro en la Ley. El art. 30 de Cartera no prevé un protocolo de coordinación donde se incluya este aspecto. Convendría estandarizar un proceso de coordinación de casos.

\section{Pertinencia y oportunidad para una reformulación}

Durante los últimos (seis) años, estamos viviendo en la CAPV una serie de cambios importantes en el marco sociojurídico de los servicios sociales. Se está conformando un nuevo escenario a partir de elementos clave como la atención a la dependencia, el enfoque comunitario, el derecho subjetivo a los servicios sociales, la diferenciación entre los servicios sociales y la garantía de ingresos o la estructuración de servicios sociales como verdadero sistema. Todo ello -sin duda- en el contexto de una profunda y excesivamente larga crisis económica con graves consecuencias en las estructuras sociales, viéndose especialmente condicionados los proyectos vitales individuales y las relaciones familiares.

Todo ello está produciendo en el ámbito profesional y político una natural preocupación sobre cuál ha de ser el desarrollo adecuado (evolución, dirección) el SVSS, en términos de identidad y dimensionamiento.

Podemos decir que nos encontramos en un momento histórico propicio en el que, aún sin tener una clara conciencia de ello, estamos iniciando la gran segunda etapa de los servicios sociales en la CAPV en el periodo democrático. Se trata de un contexto de oportunidad, en el que administraciones públicas, ciudadanía, universidades, tercer sector, entidades privadas, directivos y profesionales colaboramos para la comprensión y consideración del Sistema de Servicios Sociales como el cuarto pilar del bienestar. Es una ocasión para recuperar algunas esencias de la intervención social.

Como es propio de las etapas de cambio, los y las profesionales vivimos con frecuencia confusión y despiste. Sentimos la necesidad de buscar respuestas a cuestiones importantes como las situaciones que ha de atender el sistema, los instrumentos y la metodología que utiliza o los resultados que obtiene. También nos preocupa la adecuada organización del sistema, la complementariedad entre los sistemas del bienestar, los profesionales que se precisan en los servicios sociales o la cobertura de prestaciones y servicios.

En consecuencia, es necesario profundizar en la metodología de intervención con individuos y, sobre todo, con grupos y comunidades. Es preciso también reconocer y definir los contenidos propios de los espacios entre sistemas del bienestar, así como los procedimientos a desarrollar. Además, es conveniente encontrar fórmulas sostenibles que nos ayuden a intercambiar y visibilizar las no pocas buenas prácticas existentes en la atención primaria a través de colegios profesionales, universidades y asociaciones de profesionales. 


\section{Un (nuevo) modelo de servicios sociales de atención primaria}

Proponemos avanzar en la construcción de un sistema cuya pieza clave es la atención primaria integrada en un territorio concreto. Estos servicios sociales prestan su atención a personas, familias y colectivos en favor de su desarrollo personal y comunitario. Esta intervención, de naturaleza fundamentalmente relacional, se articula (y se comprende) en coordinación y cooperación con los demás sistemas del bienestar. Siguiendo a Silvia Navarro (2009: 12), este modelo de servicios sociales de atención primaria se orienta a partir de una concepción de la persona como sujeto activo de su propio destino (autonomía/potenciación). Así, se opta por un enfoque proactivo y preventivo de la acción social utilizando las respuestas de proximidad y la intervención socioeducativa como estrategias fundamentales.

El paso de un modelo de gestión de recursos y prestaciones económicas a un modelo de atención personalizada, basado en las capacidades y limitaciones de la persona integrada en un contexto social, requiere un cambio de actitud en responsables políticos, directivos y profesionales. Una actitud que valore el carácter preventivo de la intervención social y el grado de integración en el entorno habitual. Asimismo, este cambio requiere de un proceso de formación continua que facilite a los agentes referidos la reflexión y la adquisición de las competencias necesarias para intervenir desde una perspectiva de mejora de la calidad de vida. Esta formación es preciso que se mantenga en el tiempo en forma de apoyo técnico y supervisión.

\subsection{Los Servicios Sociales de Base son la pieza clave del Sistema Vasco de Servicios Sociales (SVSS)}

El modelo de atención e intervención de carácter comunitario por el que opta la Ley $12 / 2008$ coloca a los Servicios Sociales de Base en el centro del Sistema Vasco de Servicios Sociales. Además de ser el primer punto de acceso al sistema, tienen la responsabilidad de atender las necesidades relacionadas con la protección, la autonomía y la inclusión social, siempre con especial atención a las situaciones de riesgo. Para ello tienen la responsabilidad de la provisión y prestación de una serie de servicios (artículo 22.1) donde será fundamental un adecuado despliegue y desconcentración territorial (Casado y Fantova, 2007) para garantizar la proximidad, la intervención socioeducativa, la dinamización comunitaria y el acompañamiento social.

Por otra parte, los Servicios Sociales de Base necesitan estar adecuadamente integrados en los Servicios Sociales Municipales, de donde recibirán el apoyo técnico y para la coordinación con otros sistemas del bienestar ${ }^{8}$. Sociales.
En coherencia con este gran protagonismo, los Servicios Sociales de Base deben disponer de las dotaciones materiales y de personal necesarias para desarrollar las funciones que le son encomendadas?. Teniendo en cuenta que el Servicio Social de Base es una unidad o estructura administrativa desde la que se prestan diversos servicios establecidos en el Catá$\log 0^{10}$, sería importante que dispongan de su propia regulación que establezca un modelo común de funcionamiento. En ella deberían establecerse los criterios básicos en relación a los perfiles profesionales y funciones, estructura de gestión y funcionamiento, cargas de trabajo (casos por perfiles profesionales y servicios) y formación (Ararteko, 2010).

Los servicios sociales de atención primaria no son solamente la pieza básica y central del SVSS sino que, además, pueden estar llamados a realizar una función de agente catalizador o coordinador de la aportación de otros sistemas del bienestar cuando se trata de personas que no disponen de las capacidades o habilidades suficientes para un desenvolvimiento autónomo e integración social. En todo caso, ayudarán a la persona a comprender de forma integrada sus logros dentro de un proceso personal y/o familiar. Todo ello se tratará de manera más concreta en el epígrafe 4.4., sobre coordinación con los sistemas del bienestar.

\subsection{Opción por el modelo comunitario}

El enfoque comunitario de los servicios sociales se apoya en los múltiples antecedentes históricos -nacionales e internacionales- de la práctica de la ayuda personal en el domicilio ${ }^{11}$. Los servicios sociales de atención primaria se han denominado tradicionalmente en las diferentes legislaciones como 'comunitarios', 'generales' o 'de base'.

Este enfoque comunitario ${ }^{12}$ está relacionado con la atención y permanencia de las personas en su domicilio (frente al internamiento en instituciones colectivas, asilares u hospitalarias), propone aprovechar al máximo la capacidad natural de la comunidad (redes informales, amigos, cuadrilla, compañeros, familia), y se basa en el principio de participación de las personas y los grupos. Podemos decir con Fernando Fantova que los servicios sociales se ocupan de prevenir, paliar o corregir el ajuste entre la autonomía personal y el soporte social disponible en sus redes familiares

9 El Ararteko, en su informe extraordinario de 2010 plantea que la ratio adecuada podría ser entre 0,45 y o,66 profesionales por mil habitantes, incluyendo profesionales de trabajo social, de adminis tración y de educación social.

${ }^{10}$ Tal y como se recoge en el artículo 22 de la Ley 12/2008 de Servicios Sociales.

${ }^{11}$ Sobre esta cuestión puede verse Casado (2007).

${ }_{12}$ Sobre esta cuestión, es muy interesante el Informe del grupo de expertos ad hoc sobre la transición de la asistencia institucional a la base comunitaria (Dirección General de Empleo, Asuntos Sociales e Igualdad de Oportunidades, 2009). Basado en el derecho a vivir en la comunidad de personas con discapacidad, ancianos, niños y personas con problemas de salud mental, se explican los argumentos a favor, los desafíos clave, los principios y se plantean unas recomendaciones para realizar esta transición. 
y sociales. Este autor plantea la "promoción de la interacción en el ámbito familiar y comunitario, es decir, los apoyos a la interacción en las redes familiares y comunitarias" (Fantova, 2008: 45-48).

Durante los años sesenta y setenta, todavía en años de dictadura, el Trabajo Social Comunitario realizó una aportación significativa -no exenta de ideología- en el marco del desarrollo social local. La etapa democrática ha ido permitiendo múltiples cauces para el ejercicio de los derechos sociales y la práctica del trabajo social se ha ido circunscribiendo, casi exclusivamente, al ámbito de la intervención individual ${ }^{13}$.

El desarrollo comunitario no corresponde únicamente a los servicios sociales. En estos momentos no son pocos los planes de carácter trasversal, en los que intervienen diversas áreas y departamentos municipales (Participación Ciudadana, Juventud, Deportes, Empleo, Seguridad Ciudadana, Cultura...) con las que colaboran -a veces tímidamente- los servicios sociales (Barbero, 2010).

La intervención comunitaria requiere la existencia de comunidad (Ramos, 2000). En el contexto actual, la experiencia de permanente inseguridad e incertidumbre (Bauman, 2008) y las situaciones producidas por fenómenos como la globalización, la movilidad laboral, diversidad en los tipos de familia, la dificultad de acceso a la vivienda o el individualismo nos están empujando a reconceptualizar lo comunitario (Zamanillo, 2010: 55-59) y descubrir nuevas formas de intervención basadas en la participación y en la solidaridad.

El objeto de atención es la persona en su ámbito social. Los y las profesionales de los servicios sociales de atención primaria han de estar presentes en la vida de esa comunidad, a través de sus estructuras formales e informales.

\subsubsection{Lo primero, la accesibilidad a los servicios sociales}

El proceso -ya iniciado- hacia la universalización de los servicios sociales debe incluir un mayor esfuerzo por facilitar el acceso a ellos de la ciudadanía en general, de las personas usuarias titulares y sus personas cuidadoras o tutores. En concreto hay que prever dos aspectos: el horario de atención al público y la situación de los centros de servicios sociales, los cuales han de tener un acceso cómodo y económico.

En ese sentido, la cuestión de ampliar el horario del servicio es una estrategia imprescindible para que sus profesionales consigan una mayor presencia en el tejido comunitario, y puedan así ser 'referentes' en los diversos ámbitos formales e informales. Esto

${ }^{13}$ Las políticas de lucha contra la pobreza en la CAPV, basadas de hecho fundamentalmente en prestaciones económicas, han sido claves a partir de 1989 . puede favorecer, sin duda, la participación de la ciudadanía en la identificación, evaluación y resolución de necesidades y conflictos.

Además, hay que tener en cuenta las especiales dificultades que tienen algunas personas -como personas sin hogar, personas con enfermedad mentalpara acceder a los servicios sociales. En este sentido, es preciso establecer estrategias de flexibilización de la organización y funcionamiento de los servicios.

\subsubsection{Participación en las dinámicas comunitarias}

En relación con el enfoque comunitario propuesto por la Ley $12 / 2008$, se puede decir que los servicios sociales de atención primaria deben redirigir su atención hacia la dinamización y el desarrollo de la comunidad donde se encuentran. Conscientes de que el desarrollo comunitario no es algo que corresponda únicamente a los servicios sociales, el hecho de promover acciones en su favor va a reforzar la sensibilización y adecuada información del Sistema de Servicios Sociales hacia la ciudadanía (Ararteko, 2010). Hoy en día estas acciones pueden concretarse en las siguientes líneas:

- A través de su presencia en los órganos de participación local como el Consejo de Distrito y los Planes de Desarrollo Comunitario.

- Actuando junto al movimiento asociativo en general (asociaciones de vecinos, comerciantes, parados, tiempo libre, autoayuda, entidades de servicios sociales) y fomentando la participación en redes de apoyo informal y voluntariado.

- Participando en acciones encaminadas al afrontamiento y resolución de conflictos familiares y vecinales a través de metodologías como la mediación y negociación.

- Manteniendo contacto permanente con agentes informales significativos en las comunidades (carteros, personal de limpieza, comerciantes, porteros y presidentes de comunidades de vecinos...).

\subsubsection{Atención a las personas en su entorno habitual $^{14}$}

\section{a. El apoyo a la familia}

El papel de la familia (de los diversos modelos de familia existentes) como recurso básico para el bienestar en general y para el apoyo personal en particular, es algo que está fuera de toda duda.

${ }_{14}$ La Ley catalana 12/2007 de Servicios Sociales establece tres tipos de necesidades objeto de atención del sistema: las derivadas de la falta de autonomía, las del ámbito familiar y social (desamparo, violencia y aislamiento social) y las necesidades materiales e instrumentales. Nosotros hemos tomado como criterio diferencial del entorno habitual disponer de familia y/o apoyo o no disponer de apoyo suficiente. 
En relación con el enfoque comunitario, la promoción del apoyo familiar constituye por sí mismo uno de los ejes principales de los programas de actuación de los servicios sociales de atención primaria. Este apoyo estará enfocado a prevenir y atender necesidades derivadas de las etapas vitales que experimentan la persona y la familia. Así, este apoyo se sitúa en el contexto familiar conformado por la convivencia, la educación de los hijos, el cuidado de sus miembros, la vivencia de pareja, la adaptación a nuevas situaciones $^{15}$ (en relación con el empleo, la salud, la vivienda), la participación social o las relaciones sociales formales e informales.

Los programas que se establecen en relación con situaciones de dependencia funcional tienen como objetivo no solamente la prestación de servicios a personas afectadas, sino, también, la capacitación y apoyo personal de cuidadores principales y secundarios. Dicha intervención, que puede desarrollarse en modalidad individual y grupal, tiene una verdadera capacidad preventiva y propedéutica, y debe ofrecerse-bien planificada- para distintos momentos vitales (estados incipientes de demencias, alzhéimer, grados leves de dependencia, salidas de ingresos hospitalarios).

En las situaciones de dependencia funcional se establecerán programas y servicios que supongan apoyos para la permanencia en el hogar. Algunos autores defienden estas medidas de comunitarización asistencial dirigidas a evitar los perjuicios causados en la persona por las residencias colectivas de estancia continuada (Casado y Fantova, 2007, pág. 25-26).

Como programas de apoyo para el mantenimiento de la persona en su hogar, los servicios sociales de atención primaria cuentan con la teleasistencia, el servicio de ayuda a domicilio, los programa de acompañamiento, los programas de intervención socioeducativa ${ }^{16}$, los programas de cuidado para los cuidadores, los servicios de respiro y los centros de día.

En caso de ser necesaria una alternativa residencial, se optará por la posibilidad más idónea por tamaño y proximidad, de tal manera que se facilite la atención personalizada y las relaciones amistosas y familiares ${ }^{17}$.

Tratando del apoyo a la familia debemos tener en cuenta la frecuente realidad de falta de soporte familiar para el cuidado de niños en los primeros tres años de vida. La conciliación entre la vida laboral y familiar es muy difícil, especialmente en los casos

${ }^{15}$ Es frecuente encontrarnos en los SSB con personas que sufren diversos malestares y no disponen del apoyo social que les ayude a superarlo. Sería oportuno que en el SSB, además de las entrevistas individuales, se les ofreciera la participación en un grupo de apoyo mutuo y crecimiento personal.

${ }^{16}$ Es destacable la importancia que adquiere el Servicio de intervención socioeducativa en el borrador de Decreto de Cartera de Prestaciones y Servicios, dirigido a toda la población y no sólo a infancia como ha sido tradicional. Sociales. de familias monoparentales. Por ello son pertinentes los programas que prestan cuidado infantil en el domicilio para niños de o-18 meses. En este sentido también cumplen su función los centros de cuidados infantiles o guarderías infantiles (o-3 años).

Asimismo es preciso tener en cuenta la necesidad de apoyo de algunas familias para el adecuado ejercicio de la maternidad y paternidad. Los programas de intervención socioeducativa y psicosocial pretenden facilitar a la familia un acompañamiento a través del cual adquieran los conocimientos y actitudes para un adecuado desarrollo de las capacidades parentales de atención de sus miembros. En este caso es fundamental la coordinación con el sistema educativo. En los últimos años vamos observando por otra parte las dificultades que conllevan los procesos de reagrupación familiar de familias extranjeras. Estos programas socioeducativos pueden ser útiles con las adaptaciones precisas a las variables de interculturalidad.

\section{b. Situaciones de urgencia y emergencia social}

Las familias y, de forma especial, los ciudadanos que viven solos y no cuentan con apoyo social están expuestos a situaciones de desprotección causadas por emergencias de distinta índole, en las que estas personas ven comprometidas sus capacidades personales de autocuidado y subsistencia. Los servicios sociales han de ser capaces de proporcionar el apoyo personal necesario para afrontar estas situaciones de desprotección circunstancial o permanente ${ }^{18}$.

Es preciso destacar el potencial preventivo de un adecuado Servicio de Teleasistencia, que, además de proporcionar una sensación de seguridad, permite demandar atención urgente. El gran número de personas (potencialmente) usuarias nos anima a proponer la máxima cobertura posible y la mejora de coordinación con los servicios sociales de base. En este mismo aspecto preventivo, sería conveniente aprovechar la valiosa presencia (cuantitativa y cualitativa) de auxiliares de ayuda a domicilio, incluyendo en el diseño del SAD protocolos sencillos de observación y trasmisión de información a las profesionales de referencia en el Servicio Social de Base.

Es conveniente que los servicios sociales de atención primaria dispongan de tres modalidades de atención: ordinaria (cita previa), prioritaria y urgente (atención inmediata y, en su caso, en desplazamiento al lugar de la emergencia). Es oportuno citar en este caso la experiencia de los ayuntamientos de las tres capitales de la CAPV a través del formato Servicio Municipal de Urgencias Sociales ${ }^{19}$.

${ }^{18}$ En este sentido, la Ley $12 / 2008$ de Servicios Sociales establece como uno de sus objetivos esenciales "la atención y prevención de las necesidades personales y familiares originadas por las situaciones de emergencia” (art. 6.1 d). Así, el Catálogo de Prestaciones y Servicios prevé en su art. 22.2.6 un servicio de coordinación ad hoc.

19 Vitoria-Gasteiz inició el servicio en 1988, Bilbao, en 1999; y Donostia, en 2007. Su evolución, contenido y metodología pueden consultarse en Agirre, Estomba y Duque (2011). 
El estado de desprotección -en sentido genérico- al que nos referimos puede estar debido por causas repentinas como un ingreso por urgencia médica, una detención o un fallecimiento de la persona cuidadora, por ejemplo. Las personas afectadas son menores, personas adultas con dependencia funcional, personas con enfermedad mental, personas que viven en la calle o personas con discapacidad. Cuando se trata de incendios, accidentes, derrumbamientos, inundaciones, explosiones y otros de naturaleza similar, los servicios sociales activarán los recursos suficientes adecuando su respuesta a la magnitud de la emergencia.

La intervención de los servicios sociales en cualquier situación de emergencia (individual, grupal o colectiva), precisa de una capacidad de respuesta real, esto es, activación inmediata y desplazamiento in situ, realización de diagnóstico básico de necesidades y aplicación inmediata de recursos y prestaciones (Agirre, Estomba y Duque, 2011: 76-77).

Debe ponerse especial atención a las situaciones sobrevenidas de desprotección y para ello es imprescindible disponer de prestaciones dirigidas a afrontar necesidades de alojamiento alternativo temporal (familia con menores, convalecencia para personas sin techo), ingreso inmediato en residencia (personas mayores, personas discapacitadas) y atenciones personales y/o domésticas de urgencia, especialmente para personas mayores que viven solas (Duque y Murguía, 2011: 80-81).

Los servicios sociales realizan su intervención en coordinación con los demás recursos que intervienen en emergencias (cuerpos policiales, bomberos, sanitarios). Para garantizar a toda la ciudadanía de la CAPV el acceso a los servicios sociales en una situación de emergencia, lo más eficaz es la integración del Servicio de Coordinación de Urgencias Sociales -incluido en el Catálogo de prestaciones y servicios de la Ley $12 / 2008$ de servicios sociales- en el protocolo de activación del 112 con ámbito de actuación en la CAPV ${ }^{20}$. Este Servicio de Coordinación de Urgencias Sociales puede asumir todas las consultas telefónicas sobre temas considerados de particular importancia de cada momento (en la actualidad disponemos de servicios telefónicos para cuestiones como adolescencia -sexo, bullying-, drogas o violencia de género). En situaciones de emergencia con necesidad de desplazamiento y atención in situ, debe ser activado el servicio de la zona correspondiente por Mapa de Servicios Sociales.

\section{c. Situación de riesgo y exclusión social}

Los servicios sociales de atención primaria han de estar capacitados para atender de forma proactiva a personas en situación o riesgo de exclusión social. Las formas de organización pueden ser diversas,

${ }^{20}$ Visto así, puede desarrollarse como acción directa del Gobierno Vasco. Es inherente a este servicio que los servicios de zona sean realmente próximos y conocedores de la realidad, por eso quizás sea más adecuado que sean municipales. dependiendo del tamaño del municipio, las características geográficas, la demanda existente y otras.

Merece la pena recordar la situación de las personas que, viviendo solas, se encuentran en un progresivo deterioro psicofísico (autoabandonismo) constituyendo verdaderas situaciones de riesgo para sí mismos y para los vecinos. La acumulación de enseres, o basura, los fuertes olores, así como la falta extrema de higiene suelen originar situaciones de emergencia sanitaria, incendios, explosiones y otros (denominados síndrome de Diógenes o similar).

Se trata de intervenciones complejas por el acceso, la no disponibilidad de la persona a la intervención y la dificultad para mantener las mejoras conseguidas. Los Servicios Sociales de Base pueden detectar la situación por medio de familiares, vecinos u otros profesionales. De inicio, diseñarán una intervención coordinada con profesionales del centro de salud y, conseguida una mínima confianza, pueden plantear intervenciones de limpieza extraordinarias y, luego, de mantenimiento. Será preciso valorar si es posible y adecuado mantener a la persona en su domicilio (con SAD por ejemplo) o si es adecuado un alojamiento alternativo. En todo caso, se trata de una intervención intensiva que habitualmente requiere el concurso de profesionales de varios sistemas ${ }^{21}$.

Continuando en el ámbito de la exclusión, es preciso citar la necesidad de apoyo personal y material de los jóvenes que, recién cumplidos los 18 años, finalizan su estancia en los centros para menores extranjeros no acompañados competencia de las diputaciones forales. Son necesarios recursos de alojamiento complementados con programas educativos enfocados hacia objetivos de empleabilidad. Los programas existentes son muy escasos y muchas de estas personas pasan literalmente a vivir en la calle. En los últimos años ésta es una de las causas más claras del sinhogarismo en la CAPV.

En relación a las personas en situación de riesgo o exclusión que viven en la calle, los servicios sociales municipales deben articular una respuesta inmediata que incluya prestaciones de subsistencia (alojamiento, alimento y vestido) y de atención personal. Sin dejar de lado la importancia de las prestaciones económicas, no debemos olvidar otras como la información y asesoramiento que, mediante un adecuado acompañamiento social, facilite el acceso a los sistemas sanitario, educativo y de vivienda. El acceso a la vivienda es fundamental. Por eso es preciso disponer de programas de acceso a vivienda con acompañamiento personal.

Los procesos de inclusión social suelen ser complejos y de larga duración; el pronóstico de mejora no

${ }^{21}$ El Ayuntamiento de Bilbao está realizando un esfuerzo en los dos últimos años, gracias al cual se ha conseguido aumentar la detección de estas situaciones, estableciendo un protocolo de actuación. Son situaciones complejas en las se presentan conjuntamente indicadores de desprotección y exclusión. 
es lineal. Por eso, el acompañamiento social es fundamental para apoyar episodios recurrentes y crisis. Algunas personas consiguen altos niveles de autonomía personal y participación social. Otras, con grave deterioro personal, logran niveles de inclusión social aceptables que precisan para su mantenimiento de apoyo profesional de baja o media intensidad de manera permanente.

\subsubsection{Criterios y propuestas operativas: qué podemos hacer}

A partir del repaso realizado, se detallan a continuación una serie de criterios y propuestas operativas con las que se pretende dar respuesta a las principales deficiencias señaladas.

\section{a. Para mejorar la accesibilidad}

- Las nuevas tecnologías ya son utilizadas por la ciudadanía en muchos servicios municipales. Es conveniente que exista la posibilidad de poder realizar consultas, concertar una cita u realizar otras acciones a través de internet.

- Sería razonable que los Servicios Sociales de Base estuvieran abiertos al público cinco días a la semana en horario de mañana y tarde.

- Sería conveniente disponer de un Servicio Social de Base adaptado para atender a personas sin domicilio fijo o en situación de exclusión, diseñado con criterios de atención continuada, sin cita previa.

- Las personas con dificultades graves para el desplazamiento deben ser atendidas por los y las profesionales de los servicios sociales en el domicilio.

- El Servicio Social de Base ha de ser accesible a pie o en transporte público.

- Sería conveniente promover estrategias proactivas para atender de forma programada a personas sin las habilidades, información o apoyo social suficiente para acudir a los servicios sociales por iniciativa propia. En las estrategias de acercamiento es importante valerse de agentes mediadores como vecinos y profesionales de proximidad (como los equipos de limpieza).

- Sería importante aumentar la capacidad de detección de personas mayores que viven solas. Se trata de una estrategia anticipatoria. Puede hacerse a través de la acción permanente de un observatorio de personas mayores. Para ello pueden utilizarse diversas fuentes:

- Avisos de la ciudadanía.

- A través del Servicio Municipal de Urgencias Sociales, detectados en emergencias individuales (incendios, caídas, desorientación...).

- A través de las auxiliares de servicio de ayuda a domicilio, con funciones a modo de antena social.

- A través de los servicios de urgencias médicas.
- Por los servicios sociales de las agencias públicas de vivienda (Viviendas Municipales, Surbisa, Visesa...).

- A través de centros escolares y asociaciones de padres de alumnos.

- A través de parroquias.

- Por medio de entidades locales de voluntariado.

\section{b. Para lograr mayor participación en las dinámicas comunitarias}

- Participar de forma sistemática en la Comisión Socio-Cultural del Consejo de Distrito.

- Participar con funciones de liderazgo compartido en los Planes de Desarrollo Comunitario que el Ayuntamiento articula con carácter trasversal, con la intervención coordinada de varias áreas o departamentos.

- Conocer y mantener contacto permanente con las asociaciones de profesionales en la zona.

- Trabajar con las asociaciones de personas mayores. Además del valor en sí mismo, puede tener efectos multiplicadores en la intervención dirigida a personas mayores en una zona. Servirá para detectar situaciones de soledad, desprotección y dependencia. Se puede acercar a personas solas hacia estas asociaciones y obtener compañía, ocio, alimento.

- Situarse como referencia de las comunidades de vecinos que lo precisen para el análisis y mediación en la resolución de conflictos comunitarios.

- Fomentar los grupos de autoapoyo y autoayuda en el barrio. Participar en grupos o plataformas asociativas informales.

- Promover y participar en actuaciones preventivas con agentes de otros sistemas (por ejemplo, con programas de cuidado a cuidador o de promoción de la salud).

- Fomentar el asociacionismo y el voluntariado. Colaborar con grupos y asociaciones locales, prestando apoyo, información y asesoramiento.

- Promover estrategias para la participación y colaboración entre el movimiento asociativo de la zona y los servicios sociales públicos ${ }^{22}$.

\section{c. Para procurar atención a las personas en su entorno habitual}

- Realizar las entrevistas necesarias en el domicilio para garantizar un acompañamiento social adecuado a las necesidades de la persona. Como criterio general, podemos hablar de 3-6 meses mínimo, dependiendo de tipos de las situaciones.

${ }_{22}$ El Catálogo de Prestaciones y Servicios de la Ley 12/2008 de Servicios Sociales prevé un Servicio de Promoción de la Participación y la Inclusión Social (art. 22.1.5). Este servicio puede articular muchas y variadas iniciativas en el ámbito territorial de atención de un Servicios Social de Base. 
- Convocar grupos de apoyo y crecimiento personal. Realización de sesiones grupales dirigidas a personas que sufren diversos malestares y no disponen del apoyo social que les ayude a superarlo.

- Actividades colectivas o grupales informativas sobre recursos sociales.

- Articular la compatibilidad entre los diferentes programas y servicios que supongan apoyos para la permanencia en el hogar. Por ejemplo, compatibilizar SAD con otras prestaciones $\mathrm{y} / 0$ servicios (Centro de Día, ayuda económica por cuidados en el entorno familiar...).

- Promocionar programas de intercambio generacional.

- Promocionar programas de neto contenido comunitario, como el Banco del Tiempo.

- Promocionar programas de intervención socioeducativa con personas adultas y familias con objeto de evitar la pérdida de la vivienda.

- Potenciar la detección de situaciones Síndrome de Diógenes y similares y articular y coordinar las intervenciones de higiene, sanitarias y de servicios sociales (socioeducativa, ayuda a domicilio) oportunas.

- Promocionar programas de acompañamiento socioeducativo dirigidos a personas sin hogar para la incorporación y mantenimiento en la vivienda.

- En las situaciones de desprotección de adultos detectadas en una situación de emergencia, potenciar como primera opción el alojamiento en la red social formal o informal. Utilizar de forma subsidiaria el alojamiento hotelero o en residencias específicas para personas mayores y/o dependientes.

- Promocionar, con el objetivo de extenderlo de forma generalizada, el servicio de teleasistencia como servicio que permite la atención de urgencia a personas mayores $y$, especialmente a personas mayores que viven solas y/o con dependencia funcional.

\subsection{Modelo de atención personalizada y desarrollo personal}

Nos encontramos, como antes se ha señalado, en un momento de transición, desde un modelo de gestión y administración de recursos y prestaciones económicas hacia un modelo basado en la atención personalizada. Los objetivos a los que apunta son el desarrollo personal y autónomo, la calidad de vida y el máximo grado de integración social. El carácter preventivo, la proactividad y la intervención temprana son características básicas de este modelo ${ }^{23}$. Este modelo subraya el carácter relacional de la intervención

${ }^{23}$ En la perspectiva de perfeccionamiento y renovación metodológica y técnica, Demetrio Casado incluye el enfoque del desarrollo personal (Casado, 2007). profesional, sitúa a la persona como protagonista ${ }^{24}$ y articula la relación de ayuda desde un concepto de integralidad del ser humano. Situar a la persona en el centro supone su participación a lo largo del proceso incluyendo su derecho de autodeterminación respecto a las intervenciones ${ }^{25}$.

A continuación se exponen los elementos metodológicos clave en este modelo de atención y desarrollo personal.

\subsubsection{Procedimiento básico de intervención ${ }^{26}$}

En la Ley 12/2008 de Servicios Sociales la atención personalizada es uno de los elementos claves en el modelo de atención y de intervención (art. 8), teniendo su reflejo en el procedimiento básico de intervención (art. 19) y ampliado en los artículos 12, 13 y 14 del Decreto de Cartera de Prestaciones y Servicios. Sus ejes principales son:

a. El diagnóstico que, realizado con instrumentos de diagnóstico comunes, establecerá la existencia o no de un grado de necesidad.

b. El requisito de necesidad respecto a las contingencias establecidas de desprotección, dependencia y exclusión social, contemplando las categorías de riesgo y situación de.

c. El plan de atención personalizada, en cuyo desarrollo se incluirá seguimiento y evaluación periódica.

d. La prescripción técnica, que incluye el grado de idoneidad del servicio respecto a la necesidad de la persona.

e. El profesional de referencia que coordina el proceso de atención.

Se establecen tres tipos o modalidades de atención: ordinaria, urgente (que podríamos denominar asimismo 'prioritaria'), y en situación de emergencia social.

En la primera atención el Servicio Social de Base ofrecerá las prestaciones de "información y valoración inicial de la demanda" ${ }^{27}$. En el Servicio Social de Base se procederá a una valoración inicial de la demanda planteada con el fin de determinar si procede una intervención por parte del SVSS. Se ofrecerá la información oportuna relacionada con la demanda planteada y, en su caso, se le derivará al sistema que sea competente.

\footnotetext{
${ }^{24}$ En este caso queremos defender la competencia en la toma de decisiones y la necesidad de responsabilización como bases para la toma de conciencia, el cambio y el crecimiento personal.

${ }^{25}$ Así puede verse los derechos de las personas usuarias de Ley 12/2008 de servicios sociales (art. 9. 1).

${ }^{26}$ Véase el borrador de Decreto de Cartera de Prestaciones y Servicios (art. 18-26).

${ }^{27}$ Las definiciones pueden verse en el Anexo IV del Decreto de Cartera de Prestaciones y Servicios.
} 
De esta valoración inicial puede derivarse una demanda puntual sin que exista necesidad de realizar un seguimiento. Por el contrario, si se prevé la necesidad de seguimiento, se designará un profesional de referencia que será el encargado de realizar el diagnóstico y, si éste así lo aconseja, el plan de atención personalizada, siempre contando con el consentimiento y participación de la persona o familia (algunos autores hablan de 'codiagnóstico'). Es preciso añadir que la Ley $12 / 2008$ de Servicios Sociales establece que las personas usuarias tienen derecho a disponer de un profesional de referencia, de la evaluación o diagnóstico de sus necesidades y de un plan de atención personalizada (art. 9.1.i y h) y su incumplimiento está considerado como infracción grave (art. 90.1.d) ${ }^{28}$.

\subsubsection{Profesional de referencia y gestión de $\operatorname{caso}^{29}$}

Las raíces del case management o gestión de caso se encuentran en la etapa de desinstitucionalización que tuvo lugar en EEUU a principios de los años cincuenta. Al principio se centraba en la gestión de servicios para el cliente (vínculo positivo y operativo, continuidad de cuidados...). Más tarde incorporó funciones de soporte y consejo a clientes y familiares en relación con situaciones complejas y toma de decisiones en asuntos de la vida diaria y con la comunidad. Se ha desarrollado preferentemente en el mundo sanitario, dependencia, geriatría, gerontología, drogodependencia y salud mental.

El método de gestión de caso es idóneo para ayudar a personas con necesidades psicosociales y, sobre todo, para trabajar con situaciones complejas donde hay que manejar un conjunto de opciones, servicios y recursos y el ciudadano/a requiere orientación y consejo. La Asociación Nacional de Trabajadores Sociales estadounidense la define como: "un método de provisión de servicios por parte de un profesional que valora necesidades del cliente y de su familia, en colaboración con él, y aconseja, articula, coordina, monitoriza, evalúa, y defiende las necesidades y los intereses de sus clientes y propone un paquete de medidas y/o servicios acorde a las necesidades variantes del cliente" (National Association of Social Workers, 1998).

Las definiciones manejadas en los diferentes ámbitos coinciden en los siguientes elementos:

- El proceso como intervención profesional articulado en un tempus determinado, donde descartan las actuaciones puntuales.

- La colaboración en tres direcciones: participación del cliente y su familia, el gestor aporta su saber hacer, colaboración con los otros sistemas de protección públicos o privados, formales o informales.

${ }^{28}$ Todo ello puede verse en el art. 19 de la Ley $12 / 2008$ de Servicios Sociales.

${ }^{29}$ Debido al escaso uso de este término en los servicios sociales, incluimos algunas notas tomadas de Rimbau (2008) y Sarabia (2009).
- La identificación de necesidades, a partir de la escucha activa y el análisis de los puntos fuertes y débiles, viendo los cambios producidos.

- Un conjunto de intervenciones, de naturaleza holística y dinámica, de carácter trasversal, de coordinación y articulación, a partir del plan de trabajo elaborado con el cliente.

- Orientación hacia los resultados, analizada su viabilidad, se incluirá en el plan de intervención.

Cristina Rimbau (2009) describe estos principios como ventajas de esta metodología y plantea que, para empezar, los servicios tendremos que considerarlo "como un método no ajeno sino próximo y posible”. De hecho -afirma- "podemos constatar la coincidencia de principios, enfoque metodológico y procesos con la gestión de caso" históricamente practicado en los servicios sociales (case work).

En la bibliografía de referencia podemos encontrar diferentes modelos de gestión de caso. Nosotros podemos identificar la figura del gestor de caso con la del profesional de referencia, cuya herramienta principal es el acompañamiento social. Como veremos en su apartado específico, estos principios coinciden en gran manera con los del acompañamiento social. El o la profesional de referencia tendrá como función procurar la coherencia, integralidad y continuidad del proceso de intervención. La coordinación de todo este proceso se denomina gestión de caso.

En principio, según la Ley 12/2008 de Servicios Sociales, esta función corresponde a la trabajadora o trabajador social de base. Cuando se requiera un alto grado de intensidad de la intervención, la coordinación del caso podrá ser transferida a un o una profesional de la atención secundaria ${ }^{30}$.

Disponer de una figura profesional de referencia (FPR) es la condición básica que puede garantizar el proceso de atención personalizada. Mediante la prestación de acompañamiento ofrecerá los elementos necesarios de estabilidad y globalidad que ayuden a la persona a mantener el sentido de su proceso. Además, ha de ser una figura de apoyo y contraste, con objeto de ayudarle a mantener la coherencia entre el diagnóstico, el plan acordado y los logros conseguidos (Colegio Oficial de Trabajadores Sociales de Madrid: 2003: 22-23). Por otro lado, esta figura profesional es fundamental para ordenar e integrar la intervención realizada por los profesionales de otros servicios y/o sistemas, así como para garantizar a la persona usuaria una información homogénea.

${ }^{30}$ En mi opinión, éste es un aspecto que no queda suficientemente explicitado en la Ley y, que por ello, sería pertinente que se aclarase en el Decreto de Cartera de Prestaciones y Servicios. En el documento que ha iniciado el trámite parlamentario no se recoge nada al respecto. Quizás el lugar adecuado para incluirse podría ser el art. 30, donde trata los protocolos de derivación entre los niveles de atención primaria y secundaria, tal y como propone Eudel en sus alegaciones. 
La existencia de la figura de profesional de referencia en los servicios sociales de atención primaria no excluye la existencia de otro u otros profesionales que realicen el acompañamiento social en servicios y/o programas específicos. El primero contará con la participación y colaboración de éstos para realizar adecuadamente su función de coordinación (diagnóstico, plan de atención individualizada, evaluación) y continuidad de la atención. Sería conveniente que esta participación estuviera de alguna forma estandarizada.

En relación al asunto de la figura profesional de referencia, entendemos que es clave tratar de aplicarlo a las situaciones en que una persona está atendida en dos o más sistemas de protección de manera simultánea. Nos referimos, por ejemplo, a personas que están atendidas en centros (atención diurna) de salud mental o en centros de formación y en servicios (atención diurna y/o residencial) de inclusión social. En principio -es un tema actual de debate en el ámbito profesional- entendemos que cada sistema ha de tener una figura profesional de referencia. Es preciso que cada figura conozca y asuma, en contenido y tiempo, las competencias y funciones de su ámbito de intervención y que se realice la adecuada coordinación entre ellas, basada en los protocolos institucionalmente establecidos ${ }^{31}$. Asimismo vemos que esta coordinación se realizará con la flexibilidad indicada por el mayor o menor grado de intensidad de la intervención profesional de cada sistema. En este sentido, tenemos que contemplar la posibilidad de realizar planes de intervención compartidos, donde podamos plantear de una forma integrada los objetivos de ambos sistemas.

El deseo de un ciudadano/a de pedir una segunda opinión diagnóstica así como el deseo de elección o cambio de la figura profesional de referencia son dos cuestiones que, quizás en algún momento, habrá que abordar y regular. Estas cuestiones no aparecen en la Ley $12 / 2008$, entre los derechos de las personas usuarias de los servicios sociales (art. 9.1). En cualquier caso, seguramente la práctica cotidiana va por delante de la teoría y la legislación y, de hecho, se van resolviendo.

La introducción de esta figura profesional de referencia o gestor de caso es uno de los elementos claves que, desde una perspectiva metodológica y organizacional, conllevará cambios importantes en nuestros servicios sociales de atención primaria. Estos cambios tendrán sus implicaciones concretas en el estilo de intervención y en la mentalidad de los y las profesionales, en los planes de formación (incluida la supervisión) y en las estructuras organizativas.

${ }^{31}$ Se trata de una cuestión que, lejos de ser obvia, condiciona positiva y negativamente en gran manera los procesos personales y el funcionamiento de los servicios. Valorando las buenas prácticas existentes, debemos insistir en que unas buenas relaciones personales entre profesionales, además de no ser obligatorias ni garantistas, no son suficientes en un sistema de responsabilidad pública.
Según Begoña Pérez Eransus (2004: 93-96), la intervención social basada en la metodología de gestión de casos requiere algunas condiciones organizativas: un número abarcable de casos teniendo en cuenta la intensidad de la atención, capacidad del profesional para tomar decisiones respecto a la adjudicación de recursos, cierta continuidad y estabilidad en el equipo de profesionales, un sistema de información ágil y eficaz y mecanismos continuados de evaluación de la idoneidad, eficacia y eficiencia de la intervención.

\subsubsection{Diagnóstico y plan de atención personalizada}

La Ley de Servicios Sociales establece que se utilizarán instrumentos técnicos comunes de valoración y diagnóstico así como modelos comunes de ficha social y plan de atención personalizada ${ }^{32}$.

\section{a. Diagnóstico}

La Ley 12/2008 de Servicios Sociales establece que el diagnóstico es una prestación técnica propia del SVSS (art. 15.2.c). Junto con la valoración y la orientación, es una prestación que se realizará "siempre a través de gestión pública directa” en primaria y secundaria (art. 60.2). El SSB realizará en su primera atención una primera valoración de necesidades. Si la intervención precisara seguimiento, el profesional de referencia realizará un "diagnóstico de mayor profundidad” (art. 19.1 y 28.3.a). Si el profesional de los servicios sociales de atención primaria lo considerase conveniente, solicitará la realización de un “diagnóstico especializado" (art. 30.2) o valoración pericial al servicio correspondiente de la atención secundaria. Este diagnóstico especializado tiene carácter vinculante cuando determina el acceso a una prestación o servicio ${ }^{33}$. Esta valoración o diagnóstico servirá para establece si hay o no riesgo o si se trata de una situación declarada de desprotección, dependencia o exclusión ${ }^{34}$.

Según el Decreto de Cartera (art.19.4), para proceder al diagnóstico el profesional de referencia del servicio social de base "aplicará los instrumentos técnicos, indicadores o criterios que estime pertinentes”. Esto, en mi opinión, es una incoherencia con lo establecido en la Ley respecto a que el diagnóstico se ha de realizar con instrumentos comunes (art. 20). Es de suponer que la Ley no se refiere solamente a utilizar instrumentos comunes para el diagnóstico especializado.

En este apartado nos referiremos al diagnóstico que ha de realizar el profesional de referencia del

${ }^{32}$ Así dice el artículo 20 de la Ley 12/2008 de Servicios Sociales para garantizar la homogeneidad en los criterios de intervención.

${ }^{3}$ La Ley habla de 'diagnóstico especializado', mientras que el Decreto de Cartera de Prestaciones y Servicios dice 'valoración pericial'. En mi opinión, es más adecuado y sencillo para la práctica profesional mantener y definir 'diagnóstico especializado'.

34 Véase el art. 13.2 del Decreto de Cartera de Prestaciones y Servicios. 
servicio social de base (art. 19.1 y 28.3.a). Teniendo en cuenta las contingencias que la Ley de Servicios Sociales establece en su art. 4 (dependencia, desprotección y exclusión social), los servicios sociales de atención primaria no deben renunciar a realizar su diagnóstico desde una concepción integral de la persona. Por eso, se deberá hacer -en principio- un diagnóstico generalista, basado en la exploración de las diferentes áreas o facetas de vida de la persona y/o familia. Sería deseable -y entiendo que éste es el sentido de la Ley- que en toda la CAPV se utilizara un instrumento de diagnóstico general o primario común. Asimismo, sería interesante que los valores significativos (prevalencia) de los indicadores relacionados con cada contingencia ayudaran a prever posibles empeoramientos de la situación personal/ familiar, permitiendo así propuestas de intervención temprana. Los valores determinados de estos indicadores serán la clave para solicitar un diagnóstico especializado competencia del Servicio de Valoración y Diagnóstico de la atención secundaria.

Por lo tanto, el diagnóstico social tendrá como referencia la necesidad a la que responde. Por ello, ha de mirar constantemente al objeto del sistema de servicios sociales. En palabras de Fernando Fantova (2008), el bien que protegen los servicios sociales es la interacción humana, entendida ésta como el ajuste dinámico entre la capacidad de desenvolvimiento autónomo (autonomía personal) de la persona en sus entornos vitales y el apoyo social disponible a través de los vínculos familiares, convivenciales, comunitarios o relacionales en general (integración relacional). Lo que interesa es el ajuste dinámico en cada contexto y momento del ciclo y el proyecto vital de cada persona.

Es preciso subrayar que a través del diagnóstico pretendemos comprender la situación y a la persona en ese contexto, sus necesidades y capacidades, una situación contextualizada (visión de conjunto) y dinámica (cambiante).

No debemos identificar la valoración diagnóstica con los instrumentos y técnicas que podamos utilizar para llegar a ella ${ }^{35}$. Nuestro objetivo es comprender el conjunto que forman la persona y su situación. Por eso, recogeremos los datos (hechos) pero también atenderemos a su significado, veremos la relación entre ellos y las posibles causas. La valoración diagnóstica no consiste en redactar de una forma más o menos coherente y ordenada el conjunto de síntomas que la misma persona nos comunica.

El diagnóstico es un proceso que genera un producto dinámico. Veamos algunos elementos que nos ayudan a construir este proceso.

El proceso de atención profesional comienza habitualmente por una demanda que puede estar formulada de forma más o menos concreta (explícita

${ }^{35}$ Begoña Pérez Eransus (2004: 100) alerta de las consecuencias negativas de la "reducción burocrática". o inespecífica) o bien puede reflejar una necesidad material o personal (malestar por motivos familiares, afectivos, de salud o laborales, entre otros). En todo caso, esta demanda nos proporciona una primera información -valiosa pero no definitiva-, no sólo sobre el objeto expreso de aquélla, sino también sobre la actitud vital de la persona ante el problema, sus expectativas de resolución y cuál es su disposición a ser ayudada (Ituarte, 1992: 17-24). Es frecuente ver que la primera demanda oculte otras necesidades y preocupaciones más significativas para la persona.

A partir de esta primera demanda, iniciaremos un proceso de conocimiento para llegar a comprender la situación de la persona que demanda ser ayudada. Para ello, utilizaremos principalmente la interacción personal ${ }^{36} \mathrm{y}$, concretamente, nuestras habilidades de comunicación. La observación -como habilidad para ver y entender la conducta no verbal- y la escucha activa centrada en la persona y sus necesidades serán herramientas fundamentales en este proceso (Bermejo, 1997: 35-43). Es importante y, por eso, aconsejable, que la recogida de información no se realice solamente a través de entrevista en el despacho del servicio social de base, sino que se complete en otros espacios. En este sentido, la visita a domicilio ${ }^{37}$ es una herramienta estratégica para el diagnóstico y el plan de atención. El conocimiento físico del marco de convivencia habitual ${ }^{38}$ nos puede revelar información cualitativa clave para comprender situaciones no explicitadas y elementos simbólicos (significados) difíciles de explicar.

Toda la información obtenida puede y debe ser complementada con la que podamos obtener a través de la colaboración con otros profesionales del sistema de servicios sociales o de otros sistemas (sanitario, judicial, educativo).

En mi opinión, todos los servicios sociales de atención primaria debiéramos utilizar el mismo instrumento que incluya la información básica (establecida) para la valoración diagnóstica primaria. Este soporte debe recoger información sobre todos los ámbitos de la persona/familia. Además, es conveniente utilizar otros instrumentos que nos aporten información significativa con perspectiva histórica y relacional en determinados aspectos específicos (genograma, línea de la vida, ecomapa, fotobiografía, escala de reajuste social, logotest) [Herrera Hernández et al., 2012].

En concreto, creo que hay dos instrumentos básicos que debemos utilizar para realizar el diagnóstico primario: el Diagnóstico Social del Gobierno Vasco y el genograma familiar ${ }^{39}$. Debieran estar integrados en un mismo soporte informático, a partir del cual

\footnotetext{
${ }^{36}$ Todo ello está en relación con lo tratado en el epígrafe 'Acom pañamiento social'.

${ }^{37}$ Al respecto, puede verse Toledano (2010).

${ }^{38}$ Es igualmente aplicable a la situación de personas sin hogar: conocer donde duermen y/o viven es muy útil para comprender la situación vital de cara al diagnóstico.

${ }^{39}$ Fue desarrollado a partir de Murray Bowen.
} 
pudiera emitirse el Informe de Valoración Diagnóstica y el Plan de Atención Personalizada.

Sobre el marco de fondo de las necesidades personales y sociales, se han ido construyendo diversos modelos, indicadores e instrumentos para la realización del diagnóstico ${ }^{40}$. El Diagnóstico Social del Gobierno Vasco ${ }^{41}$, además de una identificación sociobiográfica básica de la persona, contempla la exploración en cinco ámbitos vitales desplegados en 19 dimensiones.

El genograma es la representación gráfica de una constelación (Gestalt) familiar multigeneracional (suele recoger tres generaciones) que por medio de símbolos permite recoger, registrar, relacionar y exponer categorías de información del sistema familiar, en un momento determinado de su evolución y utilizarlo para la resolución de problemas. Su estructura en forma de árbol proporciona una rápida visión de las complejas relaciones familiares y es una rica fuente de hipótesis sobre cómo un problema de uno de sus componentes puede estar relacionado con el contexto familiar y su evolución a través en el tiempo (McGoldrick y Gerson: 1987). Según John Bradshaw (2008: 116), el genograma aporta un amplio marco referencial mediante el cual se obtiene una nueva perspectiva de los síntomas y conductas problemáticas. Así, el genograma nos permite ver las adaptaciones de la familia al ciclo vital, la transmisión de pautas familiares (Bowen), los sucesos significativos (acontecimientos vitales, estresantes, tensiones en la historia familiar) y las pautas relacionales.

La construcción de un genograma supone actuar en tres planos: trazar la estructura familiar, registrar la información sobre la familia (información demográfica, información sobre el funcionamiento, sucesos familiares críticos) y delinear las relaciones familiares. Este instrumento presenta múltiples ventajas: facilita la colaboración de la persona y la cooperación de la familia, ayuda a la persona a hacerse consciente de determinados elementos de su historia personal en el marco de la historia familiar. Para los y las profesionales resulta un resumen muy eficiente por gran información que aporta y la rapidez con que se comprende. No es solamente un instrumento de recogida de información al servicio de la valoración diagnóstica. Se trata de un instrumento abierto y vivo al que se puede recurrir durante todo el proceso de ayuda.

Otro elemento -además de la demanda y la recogida de información- es la formulación de hipótesis que le permitan al profesional orientar la intervención y tener propuestas para el plan de atención. Amaya Ituarte cita tres tipos de hipótesis: descriptiva, relacional y causal (Ituarte, 1992: 29). Las hipótesis

$4^{\circ}$ En este caso, citaremos únicamente el Modelo de Diagnóstico Social de Maite Martín Muñoz (2004) -desarrollo del Manual de Indicadores para el diagnóstico social de los colegios oficiales de Trabajo Social de la CAPV (1996) - y Rejado (2006).

${ }^{41}$ Este modelo se ha tomado como base para la confección del Instrumento de Diagnóstico de Exclusión Social (en este momento contamos con un prototipo que empezaremos a probar). nos ayudarán a relacionar todos los aspectos de la persona y de su contexto, incluyendo en todo caso los puntos fuertes o potencialidades de la persona. Si la ausencia de juicio ha de estar presente en todo el proceso de atención, es en la formulación de las hipótesis y en la valoración diagnóstica donde debemos prestar especial cuidado.

La valoración diagnóstica es el resultado de la comprensión global de la situación de la persona/familia tomando como referencia sus posibilidades de funcionamiento autónomo e integrado en su contexto social. Sin olvidar las limitaciones se apoyará en las capacidades y teniendo en cuenta las relaciones entre todos los elementos de la realidad existente y sus posibles causas, establecerá nuevos elementos para un pronóstico de mejora de la situación.

En este pronóstico ${ }^{42}$ la figura profesional establecerá los ámbitos preferentes de intervención, los principales apoyos con lo que cuenta la persona, los recursos y prestaciones adecuadas así como la intensidad de apoyo profesional adecuado.

\section{b. Plan de Atención Personalizada (PAP)}

La Ley 12/2008 de Servicios Sociales (art. 19) dice que este plan de atención personalizada "definirá el conjunto de servicios y prestaciones así como la realización de un seguimiento y evaluación". El Decreto de Cartera de Prestaciones y Servicios (art. 20) por su parte, establece que este plan de atención incluirá el nombre del profesional de referencia, la prescripción técnica, los compromisos -en su caso- de la red sociofamiliar, las fechas de revisión del plan, la participación económica -si procede-, así como las necesidades de coordinación o derivación a otros sistemas de protección.

Así, el PAP debe tener en cuenta los requisitos de necesidad establecidos -sistematizados en el diagnóstico- y el grado de idoneidad de esas prestaciones para dar respuesta a las necesidades detectadas que el o la profesional establecerá en la prescripción técnica. En el PAP se establecerán los objetivos de mejora en relación con los contenidos de la valoración diagnóstica. Se trata de un plan consensuado entre la persona y el profesional. La persona debe participar en la elaboración de dicho plan ${ }^{43}$, siendo su participación la base del compromiso personal. Formalizar el PAP acordado conlleva múltiples ventajas tanto simbólicas como instrumentales (Colegio Oficial de Trabajadores Sociales de Madrid, 2003: 86-87).

Esta actitud orientada a la mejora de su situación psicosocial está en relación directa con el trabajo realizado y el grado de necesidad de cambio alcanzado durante todo el proceso, especialmente en el diag-

$4^{2}$ En síntesis, podemos decir que es la valoración profesional en relación al desarrollo previsible a partir de la identificación de los síntomas.

${ }^{43}$ En relación con los artículos 8.c y 9.1.i. 
nóstico. En cualquier caso estamos ante un proceso de crecimiento personal (no lineal ni unidireccional) que, por definición, puede ser circular, con avances y retrocesos. En este contexto adquiere su sentido el acompañamiento y la relación de ayuda profesional.

Las funciones del profesional en el proceso de elaboración y seguimiento del PAP están relacionadas con la orientación, el asesoramiento, la movilización, el contraste, la motivación y el estímulo. Sobre todo ello trataremos en el epígrafe sobre acompañamiento social.

Además de los elementos indicados por el Decreto de Cartera de Prestaciones y Servicios -señalados más arriba-, entendemos que el PAP debe incluir otros elementos adicionales, como objetivos referidos a los ámbitos del diagnóstico, compromisos o acciones del profesional y de la persona usuaria, recursos y prestaciones idóneas, marco concreto de la relación de ayuda, grado de intensidad del apoyo profesional y planificación (duración), conveniencia o no de incluir en la intervención a redes formales e informales de apoyo, así como profesionales de otros sistemas. Es preciso que se acuerden asimismo los indicadores para evaluar el proceso y los resultados contemplando la posibilidad y el procedimiento de replanteamiento el PAP.

\section{c. Acompañamiento ${ }^{44}$ social}

En el Decreto de Cartera de Prestaciones y Servicios se dice que "se entenderá por acompañamiento social la prestación, más genuina y característica de los servicios sociales, en virtud de la cual la persona participa, en interacción con una o un profesional cualificado, en una relación de ayuda que contribuye a mejorar su desenvolvimiento autónomo e integración social”.

El acompañamiento social permite a la persona usuaria contrastar su situación, explicitar sus objetivos en relación con el mantenimiento o desarrollo de su autonomía personal y su integración social -acompañamiento para la inserción- y contar con una persona de referencia a lo largo del proceso para alcanzarlos, que sea capaz de ofrecerle apoyo:

- instrumental (información, orientación y mediación para el acceso a recursos y servicios de otros sistemas así como a redes de apoyo informal familia, amistades, comunidad-y relación);

- emocional (reducción del daño, contención, soporte emocional y orientación en situaciones de crisis);

- educativo (adquisición de habilidades para la realización de actividades de la vida diaria y la integración social, modificación de actitudes);

44 'Acompañar': del latín ad con panis. 'Compañero', del latín 'el que come habitualmente su pan con'. Si comparte el pan, también comparte la vida, la conversación, los desafíos. RAE: 'participar en los sentimientos de alguien'.
- relacional (escucha activa, adquisición de habilidades para mantener o establecer relaciones sociales o personales, generación de oportunidades para el establecimiento de relaciones).

El acompañamiento social puede ser más o menos intenso en función de la necesidad de apoyo de la persona. Se entiende que cabe plantear itinerarios en los que la persona usuaria vaya variando (deseablemente reduciendo) la intensidad del acompañamiento requerido.

El acompañamiento social es una prestación continuada, realizada por una figura profesional, en el marco de una relación de ayuda solicitada o voluntariamente aceptada y con objetivos de mejora y crecimiento personal. Entre profesional y ciudadano/a se establece un compromiso mutuo basado en la disponibilidad de las partes por cumplir las acciones acordadas. Este compromiso tiene como únicas limitaciones la capacidad de decisión autónoma de las personas (sin dañar el derecho de autonomía de los otros) y la legislación vigente -para profesional y ciudadano/a- (Uriz, 2002).

Acompañar es una acción cuyo significado originario está relacionado con caminar al lado de una persona adoptando la proximidad adecuada. Debemos distinguir entre plantear nuestra atención en los servicios en clave de acompañamiento (actitud receptiva, estilo disponible) con un proceso de acompañamiento compartido y continuado (Alonso y Funes, 2009). En consecuencia, no debemos ni podemos aspirar a realizar acompañamiento a todas las personas que atendemos. En los servicios residenciales de media y larga estancia puede facilitarse si se trabaja con un PAP orientado a la incorporación social, pero no tiene que darse necesariamente, sobre todo si se trata de una atención puntual.

Este proceso de acompañamiento tiende hacia la consecución de un estatus social de ciudadanía 45 conformado por derechos y obligaciones, orientado hacia la participación y la responsabilidad social. En ocasiones tendemos a identificar seguimiento con acompañamiento. En el primero, el ciudadano adquiere un rol de observado, como objeto paciente. El acompañamiento está relacionado desde su inicio con la responsabilidad de la persona (Pérez Eransus, 2004: 102). A su vez, Joaquín García Roca plantea la función tutorial como una de las estrategias de acompañamiento y la define como la relación individualizada que integra conocimientos y experiencias, expectativas y habilidades, que media entre la necesidad y su resolución y que vincula todos los mundos vitales de manera coherente (García Roca, 1995: 22) 46 .

Teniendo en cuenta que las prestaciones y servicios del Sistema de Servicios Sociales son de naturaleza

\footnotetext{
45 Véase a este respecto Cortina (1998).
}

${ }_{46}$ Sobre la importancia del componente de mediación social en el acompañamiento, puede verse Corera (2002), citado en Pérez Eransus. 
fundamentalmente relacional, proponemos la relación de ayuda como herramienta que nos permitirá mejorar nuestra competencia profesional relacional. La relación de ayuda está formada por un conjunto de conocimientos (saber), un serie de capacidades o habilidades (saber hacer) y algunas actitudes necesarias para establecer un vínculo positivo con el ciudadano/a que, con frecuencia, sufre (Bermejo, 1997 y 2008).

Desde la psicología, y sobre todo a través de las escuelas de psicoterapia, el concepto de la relación de ayuda se va enriqueciendo y diversificando continuamente. Carls Rogers dice que es aquella en la que uno de los participantes intenta hacer surgir, de una o ambas partes, una mejor apreciación y expresión de los recursos latentes del individuo y un uso más funcional de éstos (Rogers, 1986: 46). Georg Dietrich define el counseling ${ }^{47}$ como una relación auxiliante en la que el consejero intenta estimular y capacitar al sujeto para la autoayuda. La relación auxiliante busca más bien crear un clima e iniciar un diálogo con el sujeto que permita a éste aclararse sobre su propia persona y sus propios problemas, liberarse y encontrar recursos para la solución de sus conflictos, y activar siempre su propia iniciativa y responsabilidad (Dietrich, 1986: 14). Otras corrientes como la Logoterapia de V. E. Frankl han realizado interesantes aportaciones ${ }^{48}$.

Hay diferentes estilos para practicar la relación de ayuda. Dependiendo de la disposición del profesional, puede estar centrada en el problema o centrada en la persona. Según el uso del poder que haga el profesional, puede ser directiva o facilitadora. De la combinación de estos dos ejes obtenemos estilos diversos, como autoritario, paternalista, democrático-cooperativo o participativo-empático. En el ámbito de los servicios sociales optaremos por un enfoque centrado en la persona en coherencia con el planteamiento de integralidad y una concepción holística de la persona.

Viendo la relación de ayuda como proceso, entendemos que la persona ayudada realiza un pasaje desde la exploración del problema que está viviendo, la comprensión y el significado del mismo, el cambio de actitudes y de comportamiento para superarlo o vivirlo de forma más adecuada a las posibilidades del momento (Bermejo, 1997: 93-99).

Si hacemos un plan de acción para un cambio efectivo, ayudaremos a establecer objetivos significativos para la persona, verificables y realistas. Dice Giordani que iniciar este proceso significa encontrar una orien-

47 Aceptando las matizaciones que establezcan los especialistas en la materia, aquí identificamos counseling con 'relación de ayuda', por verlo así en algunas publicaciones.

${ }^{48}$ Logoterapia (Viktor Emil Frankl, 1905-1997), escuela de psicoterapia también llamada $3^{\underline{a}}$ Escuela Vienesa, después de Freud y Adler. Parte de un concepto antropológico que otorga a la persona una dimensión espiritual, además de la física y psíquica. Establece la voluntad de sentido de la vida como máxima motivación de la persona y su ausencia como origen de profundas crisis existenciales. tación de vida capaz de dar significado positivo a la propia existencia, usando la creatividad y la productividad de la que se es capaz (Giordani, 1997: 247, cit. en Bermejo, 1997: 98). La persona va descubriendo progresivamente su realidad, va llegando a sus propias conclusiones, va tomando conciencia de lo que necesita cambiar.

El acompañamiento supone la construcción de una interacción entre la persona y el profesional. El profesional realiza una oferta de acompañamiento que la persona puede o no aceptar (capacidad de elección). El grado de intensidad en el proceso de acompañamiento vendrá indicado por la necesidad y disponibilidad de la persona a ser acompañada ${ }^{49}$. En relación a lo tratado en la valoración diagnóstica, debemos aprender a descubrir el impacto vital (significado) de los hechos en las personas (Funes, 2011).

\subsubsection{Criterios y propuestas operativas: qué podemos hacer}

Nuevamente, a partir del repaso realizado se identifican los criterios y propuestas operativas que cabe aplicar:

- Promover las estrategias formativas y organizativas necesarias para adoptar el modelo de atención personalizada y desarrollo personal.

- Realizar acciones de formación dirigidas a la adquisición y mejora de actitudes, conocimientos y habilidades relacionadas con la metodología de gestión de caso, relación de ayuda, diagnóstico, plan de atención personalizada, y acompañamiento social.

- Garantizar dinámicas trimestrales de supervisión de equipo profesional.

- Promover un modelo de intervención articulada, planificada y continuada.

- Utilización del Diagnóstico Social del Gobierno Vasco y el Genograma Familiar.

- Sería conveniente establecer un estándar de intensidad del acompañamiento. Por ejemplo: baja (1-2 sesiones/año), media (3-6 sesiones/ año) y alta intensidad (7-12 o más sesiones/año).

- Disponer de condiciones materiales y temporales adecuadas para la atención personal de acompañamientos social: sala cerrada, sin interrupciones, periodos de entre 45 y 60 minutos para entrevista.

- Sería conveniente establecer una ratio de personas/familias (casos) en relación con el estándar de intensidad establecido. Esta planificación tendrá en cuenta la proporción de jornada dedicada a intervención directa-indirecta, los días de

49 Si cruzamos la variable 'grado de intensidad de acompañamiento' (eje horizontal) con la variable 'exigencia en objetivos' (eje vertical), vemos las diferentes zonas o situaciones en que puede encontrarse una persona. 
atención directa y entrevistas diarias, la formación o las sesiones de equipo.

- Fomentar y sistematizar la coordinación con los y las profesionales de los servicios o centros de organizaciones del tercer sector para la realización del diagnóstico, el plan de atención y su evaluación continua.

\subsection{Coordinación con los sistemas del bienestar}

Partiendo de una concepción integral de la persona, es obvio que la coordinación entre los diferentes sistemas o políticas públicas con fines sociales es algo deseable y necesario si queremos que la acción pública esté realmente orientada a la ciudadanía (Casado, 2002: 89-105).

Las políticas públicas que comparten este fin social tan amplio como es el bienestar se dirigen a la ciudadanía a través de su estructuración en sistemas. Por esto, según nuestras necesidades y demandas, solicitamos atención en el sistema sanitario, sistema educativo, sistema de empleo, sistema de rentas de garantía de ingresos, sistema de vivienda y sistema de servicios sociales.

La responsabilidad o competencia de cada sistema no es algo estático y terminado. Los sistemas se van construyendo y cambiando y la estructuración de la Administración Pública se transforma y adapta constantemente a las circunstancias sociopolíticas.

\subsubsection{Necesidad de coordinación y cooperación}

El sistema de servicios sociales tiene como finalidad prevenir y atender los desajustes y las necesidades derivadas de situaciones de dependencia, desprotección y exclusión. En servicios sociales nos encontramos frecuentemente con situaciones o demandas complejas que requieren respuestas integrales, en las que es preciso articular intervenciones y herramientas aportadas por varios sistemas. La coordinación y cooperación entre los sistemas del bienestar está sustentada en varias razones:

1. Las personas sentimos y vivimos nuestras necesidades de una forma integrada. Cada persona vive su existencia como un todo y las necesidades ligadas a la protección son difícilmente disociables.

2. Algunas situaciones de necesidad precisan intervenciones simultáneas y combinadas ya que es oportuno la cobertura de necesidades propias de dos o más sistemas. Por ejemplo, la persona sin hogar que necesita alojamiento y cuidados sanitarios en una situación de convalecencia ${ }^{50}$.

${ }^{50}$ Son muchas las situaciones en las que son pertinentes las prestaciones simultáneas de varios sistemas: atención de salud mental y alojamiento de servicios sociales, incorporación a la vivienda con programa de acompañamiento socioeducativo, acompañamiento socioeducativo a familias con menores absentistas, intervención socioeducativa con menores infractores, atención social a detenidos,
3. Nuestra intervención pretende, por un lado, garantizar el acceso a los otros sistemas -articulando adecuadamente el proceso de derivación entre ellos- ya que la detección de la situación de necesidad puede darse en cualquier sistema, y por otro, apoyar el mantenimiento de la prestación, acompañando el proceso de ajuste de la persona que demanda a su nueva situación. Este apoyo colaborará a que la persona adquiera y/o mantenga las capacidades y habilidades para funcionar de la forma más autónoma posible.

4. La eficacia y eficiencia de la intervención de los sistemas está condicionada por las actuaciones coordinadas (intercambio de información, objetivos compartidos, mensajes coherentes).

5. La intervención preventiva y temprana tiene beneficios claros para las personas afectadas y para el gasto de los distintos sistemas.

En función de los objetivos que se pretendan, podemos contemplar distintos grados de coordinación y cooperación. Desde los servicios sociales de atención primaria debemos establecer estrategias de coordinación sistematizada (estable) con los siguientes sistemas: Sistema Sanitario, Sistema Educativo, Sistema de Empleo, Sistema de Vivienda, Sistema Jurídico-Penal.

El contenido de coordinación entre los servicios sociales y estos otros sistemas tendrá como finalidad garantizar el acceso y el mantenimiento de las personas a los bienes y prestaciones que cada sistema le proporciona. En realidad estamos hablando de ese ajuste entre la capacidad de desenvolvimiento autónomo de la persona y las posibilidades de apoyo social con las que cuenta.

En consecuencia, añadimos el prefijo ‘socio-’ para identificar la naturaleza compartida de una intervención, prestación o espacio. Así, empleamos las denominaciones sociosanitario, socioeducativo, sociolaboral, sociohabitacional y sociojurídico. Este espacio compartido entre sistemas puede concretarse en diversos modelos y que, atendiendo a las prácticas que se desarrollan, podríamos graduarlas en tres modalidades:

1. Coordinación puntual: cuando se realiza una coordinación concreta en función de las necesidades de las personas atendidas (casos). De esta forma, tenemos las derivaciones entre servicios (más o menos protocolizadas), información complementaria relacionada con diagnóstico, plan de atención, evaluación y otros ${ }^{51}$.

atención social a víctimas -servicios sociales judiciales-, consumo higiénico de drogas o intervención socioeducativa y prestaciones de subsistencia, por poner algunos ejemplos.

${ }^{51}$ Como ejemplo podemos citar los protocolos entre centros es colares y servicios sociales de base para derivar situaciones de posible desprotección de menores. También los protocolos de derivación entre un centro hospitalario y un centro de alojamiento para personas sin techo con programa de convalecencia. 
2. Coordinación sistematizada y estable: cuando cada sistema dispone de sus profesionales de referencia y se establecen momentos de coordinación programados y periódicos donde se realiza diagnóstico y plan de atención compartido y el seguimiento-evaluación necesario ${ }^{52}$.

3. Integración funcional: cuando un mismo equipo formado por profesionales de dos sistemas desarrollan su intervención de forma integrada, con objetivos y criterios funcionales comunes ${ }^{53}$.

Concretamente, es necesaria la coordinación y cooperación en relación a varios ámbitos:

a. Prevención: en relación a temas como: violencia de género, desprotección infantil, desprotección de adultos (aislamiento, síndrome de Diógenes), promoción de la salud, pérdida de la vivienda y otros.

b. Detección: en cualquiera de los sistemas puede detectarse una situación objeto de atención por el sistema de servicios sociales.

c. Servicios y prestaciones: intervención socioeducativa con menores y adultos, programas de apoyo y cuidados al cuidador, atención en el domicilio, grupos de autoapoyo.

\subsubsection{Coordinación y cooperación en el ámbito sociosanitario}

La coordinación y cooperación entre el sistema sanitario y el sistema de servicios sociales tiene una especial relevancia. Así podemos concluirlo no sólo a partir de la misma Ley $12 / 2008$ de servicios sociales (art. 46), sino también teniendo en cuenta la incidencia que la Ley 39/2006 de Promoción de la Autonomía Personal y Atención a las personas en situación de dependencia está teniendo en el sistema de servicios sociales 54 .

En la Ley de Servicios Sociales se reconoce entidad propia al ámbito sociosanitaro, estableciendo que la atención sociosanitaria comprenderá el conjunto de cuidados destinados a las personas que, por causa de graves problemas de salud, limitaciones funcionales o riesgo de exclusión social, necesitan una atención sanitaria y social simultánea, coordinada y estable, ajustada al principio de continuidad de la atención.

52 Por ejemplo, el Programa de Atención Psiquiátrica para Personas sin Hogar con Enfermedad Mental Grave y Duradera, desarrollado entre la Red de Salud Mental de Osakidetza y el Ayuntamiento de Bilbao.

53 Modelo de Atención Primeria sociosanitaria de Sabadell. Desde 1984 los Servicios Sociales de Atención Primaria están integrados en los trece Centros de Atención Primaria de salud que hay en la ciudad. Se basa en la atención biopsicosocial de la persona y la salud entendida como fenómeno individual y social. Tiene gran incidencia en intervención preventiva y detección temprana.

${ }^{54}$ La Ley de Salud Pública, en tramitación parlamentaria, y los proyectos de la Estrategia de Cronicidad desde 2010, plantea superar la gestión fragmentada (estructuras: hospital, atención primaria, servicios sociales) con gestión de sistema local. Plantea un sistema de cuidados más proactivo que reactivo como clave para la eficacia y sostenibilidad (Bengoa, 2012).
Por otro lado, para favorecer la coordinación e integración del trabajo social sanitario y prestar un mejor servicio a las personas atendidas, podrán constituir dispositivos exclusivamente sociosanitarios, así como unidades específicamente sociosanitarias insertas en dispositivos o establecimientos de carácter más amplio.

\subsubsection{Contenidos de los espacios entre sistemas}

Es evidente que existen estos espacios y que debemos identificar áreas o líneas concretas, sistematizar sus contenidos y construir metodología e instrumentos de intervención. En la Tabla 1 tratamos de esbozar algunas propuestas.

\subsection{Organización y gestión de los servicios sociales de atención primaria}

En este apartado se presentan únicamente dos cuestiones que son claves en este modelo de atención y desarrollo personal como son las modalidades y la continuidad en la atención.

\subsubsection{Flujo y modalidades de atención}

La primera atención ${ }^{55}$ ha de realizarse a plazo corto de tiempo (por ejemplo, en tres días) y su objetivo es recibir la primera demanda, prestar la información y valoración (derivar si es preciso) y, en todo caso, tramitar prestaciones de baja complejidad (por ejemplo, valoración de dependencia, necesidades básicas). Cuando sea preciso, orientará y prescribirá una atención continuada.

La atención continuada se iniciará con asignación de profesional de referencia e incluirá la realización de diagnóstico y plan de atención personalizado con fechas de evaluación y renovación o alta (cierre). En mi opinión, es conveniente prescribir de inicio un estándar de intensidad del acompañamiento ${ }^{56}$. En un proceso continuado de atención la unidad mes (mensual, trimestral, semestral, anual) es muy útil como referencia fácil para la persona usuaria y para la planificación del o la profesional.

Es conveniente que en los servicios sociales de base exista tanto la modalidad de atención individual como colectiva. La primera no necesita explicación por ser la más habitual (en muchos municipios casi la única) ya que ha respondido a planteamiento y metodología para la resolución inmediata de la demanda. La atención colectiva puede realizarse como apoyo a grupos establecidos, colaboración y apoyo a enti-

\footnotetext{
${ }_{55}$ Es razonable que la primera atención se organice por turnos semanales, asumiendo, como criterio general, cada profesional los casos de atención continuada de su turno de primera atención (si no existe contraindicación expresa, se evita la derivación y se favorece la continuidad). Asimismo es preciso establecer un mecanismo de reajuste equitativo en la asignación de casos.

${ }^{56}$ En el epígrafe sobre plan de atención se ha propuesto tres grados.
} 
Tabla 1. Propuestas de coordinación y cooperación entre sistemas

\begin{tabular}{|c|c|}
\hline \multirow{11}{*}{ Espacio sociosanitario } & Situaciones de dependencia funcional: valoración y prestaciones de SAAD. \\
\hline & $\begin{array}{l}\text { Personas adultas que viven solas: detección, soledad, prevención de la situación de desprotección, déficit en } \\
\text { autocuidado. }\end{array}$ \\
\hline & Programas de apoyo y atención a cuidadores: grupos de ayuda mutua (GAM), alzhéimer y otras demencias. \\
\hline & Conflictos intrafamiliares: malos tratos, violencia de género. \\
\hline & Programas de atención asertivo-comunitaria (TAC) para personas con enfermedad mental en el domicilio. \\
\hline & Situaciones de exclusión grave: personas sin hogar. \\
\hline & Personas enfermas crónicas atendidas en su domicilio. \\
\hline & Programas de atención infantil y detección temprana. \\
\hline & Adicciones. \\
\hline & $\begin{array}{l}\text { Programas y recursos sociosanitarios: plazas residenciales (generales y específicas -VIH y PSH-, sala de } \\
\text { consumo higiénico. }\end{array}$ \\
\hline & Atención en situaciones de urgencia: violencia de género, síndrome de Diógenes, entre otras. \\
\hline \multirow{4}{*}{ Espacio socioeducativo } & Situaciones de absentismo escolar. \\
\hline & Situaciones de inadaptación y fracaso escolar. \\
\hline & Situaciones de riesgo o desprotección de menores: déficit en necesidades básicas, malos tratos, agresividad. \\
\hline & Coordinación con los Programas de Cualificación Profesional Inicial (PCPI). \\
\hline \multirow{5}{*}{ Espacio sociohabitacional } & Problemáticas personales/familiares que provocan impagos. \\
\hline & Conflictos vecinales. \\
\hline & Viviendas de inclusión: programas de vivienda social acompañada (acompañamiento social). \\
\hline & Colaboración con los servicios y programas de vivienda pública (viviendas municipales, Alokabide, Bizigune). \\
\hline & Colaboración con los servicios de mediación para afrontar el sobrendeudamiento por créditos hipotecarios. \\
\hline \multirow{5}{*}{ Espacio sociolaboral } & Protocolo de coordinación y derivación con Lanbide. \\
\hline & Situaciones de exclusión. \\
\hline & Situaciones de baja o nula empleabilidad. \\
\hline & Situaciones de incapacidad manifiesta. \\
\hline & Coordinación con Centros de Empleo protegido. \\
\hline \multirow{6}{*}{$\begin{array}{l}\text { Espacio sociojurídico y } \\
\text { penal }\end{array}$} & Situaciones atendidas en el Servicio de Atención a la Víctima. \\
\hline & Situaciones atendidas en el Servicio Atención al Detenido. \\
\hline & Penas alternativas. Trabajos para la comunidad. \\
\hline & Procesos de incapacitación. \\
\hline & Procesos de separaciones y divorcios. \\
\hline & Procesos de regularización. \\
\hline
\end{tabular}

Fuente: Elaboración propia.

dades voluntarias o bien a grupos organizados en el propio servicio social de base. Esta intervención social grupal se planificará en referencia a los servicios de competencia municipal recogidos en el Catálogo de prestaciones y Servicios (art. 22.1 de ley de servicios sociales). Los grupos pueden organizarse en relación a diversos factores de interés: necesidades, objetivos, ámbito (escolar, familiar, de salud), grupos de edad o intereses comunes, por ejemplo.

La intervención grupal nos ofrece algunas ventajas como la complementariedad, la rentabilización del tiempo, la trascendencia de lo individual (Colegio Oficial de Trabajadores Sociales de Madrid, 2003: 96-100). Puede concretarse en diversos tipos de grupos, por ejemplo: grupos de información sobre programas (prestaciones económicas, ayuda a domi- cilio, adopción, acogimiento familiar, implantación de nuevos recursos sociales en la zona), grupos de crecimiento personal, grupos de debate, grupos de ayuda mutua (en torno a situaciones personales varias), grupos de madres y padres, grupo de apoyo a la persona cuidadora, grupo de abuelos y abuelas, grupos de preparación a la jubilación, grupos socioeducativos.

\subsubsection{Continuidad de la atención entre atención primaria y secundaria}

Además de ser clave para que se haga efectivo un derecho a cualquier prestación o servicio, también desde el punto de vista organizativo y de gestión es importante que la ciudadanía vea garantizada la continuidad en su proceso de atención. Ello se podrá 
conseguir si existen (y se cumplen) unos protocolos de derivación y coordinación entre los servicios sociales de atención primaria y secundaria.

La continuidad de la atención es un argumento básico del modelo comunitario y de atención personalizada y desarrollo personal. Su incumplimiento puede incidir gravemente en el proceso de atención a las personas y, en mi opinión, está directamente condicionado por el adecuado funcionamiento y disponibilidad de plazas del Servicio de Valoración y Diagnóstico del nivel de atención secundaria (Servicio 2.1. del Catálogo de Prestaciones y Servicios de la ley de servicios sociales) y por la adecuada coordinación entre los dos niveles para la transferencia del profesional de referencia.

Desde un punto de vista más operativo y para resolver la distancia administrativa existente entre la atención primaria y secundaria, así como con otros sistemas del bienestar, proponemos a continuación algunos criterios y herramientas que pueden favorecer la continuidad de la atención y la coordinación y cooperación entre sistemas:

- Desarrollo informático global: sería conveniente disponer de una única herramienta informática para toda la CAPV (que incluya los tres niveles administrativos) donde se pudiera gestionar de forma integrada los instrumentos comunes (ficha social, diagnóstico primario y el especializado, plan de atención personalizada), así como los servicios incluidos en el Catálogo y Cartera de Prestaciones y Servicios. Asimismo debería prever los sistemas de conexión necesarios con servicios de otras administraciones (departamentos de Padrón, Hacienda, Vehículos, Seguridad Social o Lanbide, entre otros).
- Historia Social Electrónica Única (HSEU): su mayor interés está en conseguir una historia social integrada y única. Permitiría integrar la intervención social realizada en el sistema sanitario, educativo, de vivienda, de empleo y de servicios sociales. Manteniendo los diferentes espacios de intervención, facilita la comunicación entre profesionales y favorece una atención más efectiva y eficiente. También permite al profesional una visión integrada y estructurada. Se evitaría solicitar a la persona usuaria de forma reiterada la misma información.

- Coordinación estable entre ayuntamientos y diputaciones forales: sería conveniente establecer cauces de coordinación estable para: uno, supervisar el adecuado funcionamiento de los protocolos de coordinación y derivación; dos, tratar y resolver las posibles discrepancias técnicas; y tres, para coordinar sus planificaciones de servicios y aprovechar sinergias en aspectos como la evaluación, investigación y gestión del conocimiento.

- Mesas Técnicas de Distrito (MTD): se trataría de un órgano formal, a nivel de Distrito Municipal, formado de manera estable por representantes de centros de salud, centros educativos, servicios sociales de base, agencia local de vivienda y servicios de empleo. Su función, que no incluye la coordinación de casos, sería la coordinación de estrategias de detección de necesidades y atención a la población y la realización de acciones comunitarias conjuntas para mejorar el bienestar de la población de su ámbito geográfico (campañas preventivas o de concienciación). Sería interesante su relación con el Consejo de Distrito. 
AGIRRE, J. A.; DUQUE, J. M.; y ESTOMBA, I. (2011): “Acción social municipal en situaciones de urgencia y emergencia social. Experiencia de las capitales de la CAPV", Zerbitzuan, no 49, págs. 71-80 [〈http://dx.doi.org/10.5569/1134-7147.49.06)]

ALONSO, I.; y FUNES, J. (2009): “El acompañamiento social en los recursos socioeducativos”, Educación Social, nำ 42, págs. 28-46.

ARARTEKO (2011): Informe anual al Parlamento Vasco, Vitoria-Gasteiz, Ararteko.

- (2010): La situación de los servicios sociales de base en la CAPV. Informe extraordinario del Ararteko al Gobierno Vasco, Vitoria-Gasteiz, Ararteko.

ÁREA DE ACCIÓN SOCIAL (2012): Memoria 2011 Txostena, Bilbao, Ayuntamiento de Bilbao [khttp://goo. $\mathrm{gl} / 1 \mathrm{fPBV}\rangle]$

ARENAS, M. (2011): “Crítica y razón de los servicios sociales de base. Atención y proactividad en el Estado social”, Zerbitzuan, nํ49, págs. 39-53 [«http:// dx.doi.org/10.5569/1134-7147.49.04'].

BARBERO, J. M. (2010): "Retos metodológicos en trabajo social comunitario", en MARTÍNEZ, E.; y PEÑA, L. (coords.), III Jornada de Trabajo Social: REDefiniendo el trabajo comunitario (Vitoria-Gasteiz, 25 de marzo de 2010) / Gizarte Langintzako III. Jardunaldia: jardute komunitarioa argituz eta saretuz (VitoriaGasteiz, 2010eko martxoak 25), Vitoria-Gasteiz, Escuela Universitaria de Trabajo Social [rhttp:// www.gizarte-langintza.ehu.es/p26o-content/ es/contenidos/informacion/jornadas congresos_cursos/es_jornadas/adjuntos/ Publicacion_III_Jornada.pdf $\rangle$.

BAUMAN, Z. (2008): Comunidad, Madrid, Siglo XXI.

BENGOA, R. (2012): “Hay soluciones (II). El SNS 2012: la integración como modelo hacia la sostenibilidad", en BENGOA, R., Rafael Bengoa [bitácora personal], 7-I [rhttp://www.rafaelbengoa.com/2012/01/07/ hay-soluciones-ii/>].

BERMEJO, J. C. (2008): “Competencias 'blandas' en la relación profesional", Servicios Sociales y Política Social, no 83, págs. 87-108.
- (1997): Apuntes de relación de ayuda, Madrid, Centro de Humanización de la Salud.

BRADSHAW, J (2008): Secretos de familia. El camino hacia la autoaceptación y el rencuentro, Barcelona, Obelisco.

CASADO, D. (2007): "Objetivos permanentes y enfoques de los servicios sociales", en CASADO, D.; y FANTOVA, F. (coords.), Perfeccionamiento de los servicios sociales en España. Informe con ocasión de la Ley sobre la autonomía y la dependencia, Madrid, Fundación Foessa, págs. 268-280.

- (2002): Reforma política de los servicios sociales, Madrid, Editorial CCS.

CASADO, D.; y FANTOVA, F. (coords.) [2007]: Perfeccionamiento de los servicios sociales en España. Informe con ocasión de la Ley sobre la autonomía y la dependencia, Madrid, Fundación Foessa.

COLEGIO OFICIAL DE TRABAJADORES SOCIALES DE MADRID [2003]: Manual para el trabajo social de acompañamiento en los itinerarios de inserción, Madrid, Colegio Oficial de Trabajadores Sociales de Madrid.

CORERA, C. (2002): “Los servicios sociales de atención primaria ante la desigualdad y los nuevos procesos de exclusión", en Congreso de Servicios Sociales de Atención Primaria. 20 años de Servicios Sociales en el Ayuntamiento de Murcia. 28 y 29 de noviembre de 2001 [actas], Murcia.

CORTINA, A. (1998): Ciudadanos del mundo: hacia una teoría de la ciudadanía, Madrid, Alianza.

DIETRICH, G. (1986): Psicología general del counseling, Barcelona, Herder.

DIRECCIÓN GENERAL DE EMPLEO, ASUNTOS SOCIALES E IGUALDAD DE OPORTUNIDADES (2009): "Informe del grupo de expertos ad hoc sobre la transición de la asistencia institucional a la base comunitaria. Bruselas. Comisión Europea”, Zerbitzuan, nํ49, págs. 147-160 [<http://dx.doi. org/10.5569/1134-7147.49.12〉]. 
DUQUE, J. M.; y MURGUÍA, M. J. (2011): "La emergencia social: ámbito (privilegiado) de intervención para los servicios sociales. Gestión en el Ayuntamiento de Bilbao", Servicios Sociales y Política Social, no 94, págs. 69-82.

FANTOVA, F. (2008): Sistemas públicos de servicios sociales. Nuevos derechos, nuevas respuestas, serie Cuadernos Deusto de Derechos Humanos, no 49, Bilbao, Universidad de Deusto.

FRANKL, V. E. (1981): El hombre en busca de sentido, Barcelona, Herder.

FUNES, J. (2011): Reflexiones y prácticas sobre el acompañamiento en la incorporación social [〈http://www.jaumefunes.com〉].

GARCÍA HERRERO, G.; y RAMÍREZ NAVARRO, J. M. (2012): Índice de desarrollo de los servicios sociales 2012, Madrid, Asociación Estatal de Directores y Gerentes en Servicios Sociales [«http://www. directoressociales.com/images/documentos/ SERVICIOS\%20SOCIALES/\%C3\%ADndice\%20 DEC.pdf $\rangle]$.

GARCÍA ROCA, J. (1995): Contra la exclusión. Responsabilidad política e iniciativa social, Bilbao, Sal Terrae.

GIORDANI, B. (1997): La relación de ayuda. De Rogers a Carkhuff, Bilbao, Descleé de Brouwer.

HERRERA HERNÁNDEZ, J. M. et al. (2012): “Una propuesta metodológica para el diagnóstico sociosanitario de casos", Trabajo Social y Salud, no 71 , págs. 43-51.

ITUARTE, A. (1992): Procedimiento y proceso en trabajo social clínico, Madrid, Siglo XXI.

MARTÍN MUÑOZ, M. (1996): Manual de indicadores para el diagnóstico social [<http://ctinobar.webs.ull. es/1docencia/Poltsociale/MAITE.pdf〉].

MCGOLDRICK, M.; y GERSON, R. (1987): Genogramas en la evaluación familiar, Barcelona, Gedisa.

MINISTERIO DE SANIDAD, POLÍTICA SOCIAL E IGUALDAD (2011): Configuración de una red local de atención a personas sin hogar integrada en el Sistema Público de Servicios Sociales. Cien argumentos y propuestas, serie Informe, Estudios e Investigación 2011, Madrid, Ministerio de Sanidad, Política Social e Igualdad [<http://www.msps.es/gl/novedades/ docs/10oargumentosEspayol.pdf>].

NATIONAL ASSOCIATION OF SOCIAL WORKERS (1992): Social Work Best Practices. Healthcare Case Management Standards, Washington, National Association of Social Workers [khttp://www. sswlhc.org/docs/swbest-practices.pdf)].

NAVARRO, S. (2009): Modelo de Servicios Sociales Básicos. Una apuesta por repensar y mejorar la Acción Social territorial desde la Administración Local, Barcelona, Ayuntamiento de Barcelona [rhttp:// w3.bcn.es/fitxers/acciosocial/libre modeloserveissocialscastelladefinitiu.120.pdf〉].

PAÍS VASCO (2008): “Ley 12/2008, de 5 de diciembre, de Servicios Sociales", Boletín Oficial del País Vasco, 24-12-2008, ํㅡ 246, págs. 31.84031.924 [/http://www.euskadi.net/bopv2/ datos/2008/12/0807143a.pdf〉].
PÉREZ ERANSUS, B. (2004): “El acompañamiento social como herramienta de lucha contra la exclusión", Documentación Social, no 135 , págs. 89-107 [<http://www.caritas.es/ imagesrepository/CapitulosPublicaciones/485/ Doc.\%20Social\%20135\%20Capitulo\%205. pdf>].

RAMOS, C. (2000): "Enfoque comunitario, modernidad y postmodernidad. El trabajo social con la comunidad en tiempos de globalización", Alternativas. Cuadernos de Trabajo Social, no 8.

REJADO, M. (dir.) [2006]: Diagnóstico e intervención social. Herramienta informática para el trabajo social, Vitoria-Gasteiz, Gobierno Vasco.

RIMBAU, C. (2009): “Tenemos prácticas profesionales próximas a la gestión de caso, que deberían ser identificadas y difundidas" [entrevista], en Gizarte.doc. Boletín Documental sobre Servicios Sociales e Intervención Social, $\mathrm{n}$ 우 39, págs. 5-7 [<http://www.siis.net/documentos/ gizarte/Numero39.pdf $\rangle]$.

- (2008): “La gestión de casos”, en CASADO, D. (dir.) [2008]: Coordinación (gruesa y fina) en y entre los servicios sanitarios y sociales, Barcelona, Editorial Hacer, págs. 187-202.

SARABIA, A. (2009): "Los agentes de la gestión de caso. Perfil profesional”, en Políticas Sociales en Europa, $\mathrm{n}-\mathbf{0} 25-26$.

- (2007), “Propuestas de mejora en la organización y gestión de los servicios sociales. Diagnóstico funcional y sugerencias de cambio", en CASADO, D.; y FANTOVA, F. (coords.), Perfeccionamiento de los servicios sociales en España. Informe con ocasión de la Ley sobre la autonomía y la dependencia, Madrid, Fundación Foessa, págs. 334-342.

TOLEDANO, L (2010): "La visita a domicilio: instrumento de diagnóstico, de seguimiento y de aprendizaje", Servicios Sociales y Política Social, $\mathrm{n}^{0} \mathbf{9 1}$, págs. 82-91.

UCEDA-MAZA, F. X.; y GARCÍA-MUÑOZ, M. (2010). “Los Servicios Sociales en España: itinerarios comunes, escenarios divergentes. ¿Cuál debería ser el mínimo común de protección social?", Servicios Sociales y Política Social, no 89, págs. 83-98.

URIZ, M. J. (2002): Autonomía y corresponsabilidad en el Trabajo Social, en OLZA, M.; y HERNÁNDEZ ARISTU, J. (comps.): Trabajo Social: cuestiones sobre el qué y el cómo, Zaragoza, Certeza.

ZAMANILLO, T. (2010): "La construcción de la comunidad de hoy liberándola de sus viejos mitos", en MARTÍNEZ, E.; y PEÑA, L. (coords.), III Jornada de Trabajo Social: REDefiniendo el trabajo comunitario (Vitoria-Gasteiz, 25 de marzo de 2010) / Gizarte Langintzako III. Jardunaldia: jardute komunitarioa argituz eta saretuz (Vitoria-Gasteiz, 2010eko martxoak 25), Vitoria-Gasteiz, Escuela Universitaria de Trabajo Social [«http://www.gizarte-langintza. ehu.es/p26o-content/es/contenidos/ informacion/jornadas_congresos_cursos/es_ jornadas/adjuntos/Publicacion_III_Jornada. pdf〉]. 